\title{
The Mediating Effects of Autonomy, Competence, and Relatedness during Couple Leisure on the Relationship between Total Couple Leisure Satisfaction and Marital Satisfaction
}

\author{
Miriam Puerta Amato \\ Brigham Young University - Provo
}

Follow this and additional works at: https://scholarsarchive.byu.edu/etd

Part of the Recreation Business Commons

BYU ScholarsArchive Citation

Amato, Miriam Puerta, "The Mediating Effects of Autonomy, Competence, and Relatedness during Couple Leisure on the Relationship between Total Couple Leisure Satisfaction and Marital Satisfaction" (2013). Theses and Dissertations. 4057.

https://scholarsarchive.byu.edu/etd/4057

This Thesis is brought to you for free and open access by BYU ScholarsArchive. It has been accepted for inclusion in Theses and Dissertations by an authorized administrator of BYU ScholarsArchive. For more information, please contact scholarsarchive@byu.edu, ellen_amatangelo@byu.edu. 
The Mediating Effects of Autonomy, Competence, and Relatedness During Couple Leisure on the Relationship Between Total Couple Leisure Satisfaction and Marital Satisfaction

\author{
Miriam Puerta Amato
}

\begin{abstract}
A thesis submitted to the faculty of
Brigham Young University

in partial fulfillment of the requirements for the degree of

Master of Science
\end{abstract}

Neil Lundberg, Chair

Peter J. Ward

Ramon Zabriskie

Department of Recreation Management

Brigham Young University

June 2013

Copyright (C) 2013 Miriam Puerta Amato

All Rights Reserved 


\begin{abstract}
The Mediating Effects of Autonomy, Competence, and Relatedness During Couple Leisure on the Relationship Between Total Couple Leisure Satisfaction and Marital Satisfaction

Miriam Puerta Amato

Department of Recreation Management, BYU

Master of Science
\end{abstract}

This study tested Self-Determination Theory as a possible explanatory framework to understand the relationship between total couple leisure satisfaction and marital satisfaction. The three psychological needs of autonomy, competence, and relatedness - fundamental components of Self-Determination Theory-were measured through the Fulfillment of Psychological Needs during Couple Leisure (FPNL) scale and were tested as mediators. The analysis of five structural equation models confirmed the relevance of the Self-Determination Theory in explaining the relationship between couple leisure satisfaction and marital satisfaction. Although autonomy and competence were significant mediators, relatedness consistently appeared as the strongest mediator suggesting that the fulfillment of this psychological need is particularly important for relationship functioning and well-being. Implications to couple leisure are discussed.

Keywords: Self-determination theory, autonomy, competence, relatedness, total couple leisure satisfaction, marital satisfaction. 


\section{ACKNOWLEDGEMENTS}

To my parents Homero and Sandra, who supported me financially and emotionally. To my sister Claudia, for keeping me in her prayers. To my siblings and relatives, for their encouragement. To my friend Evan Manning, for walking extra miles to help me. To my committee chair, Neil Lundberg, and committee members, Peter Ward and Ramon Zabriskie,

for their patience and perseverance. Most of all, to my Father in Heaven, who invited me and placed me in this arduous journey. He makes me victorious. 


\section{Table of Contents}

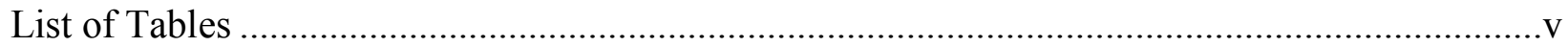

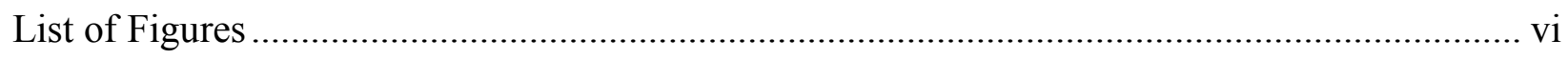

The Mediating Effects of Autonomy, Competence, and Relatedness During Couple Leisure on the Relationship Between Total Couple Leisure Satisfaction and Marital Satisfaction ............1

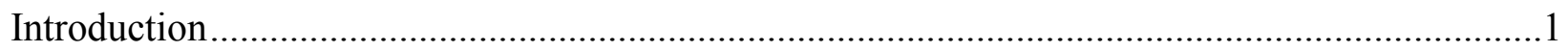

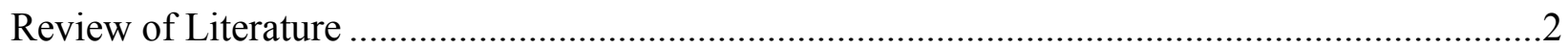

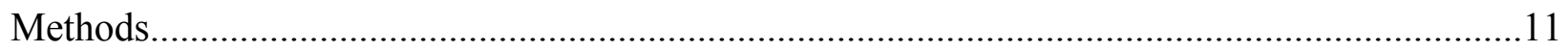

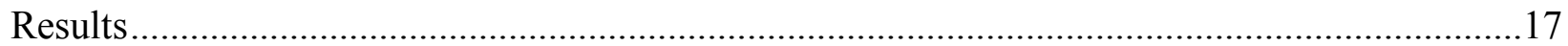

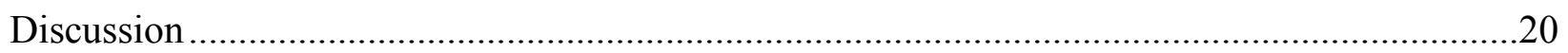

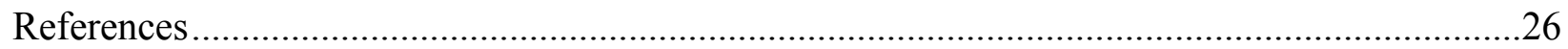

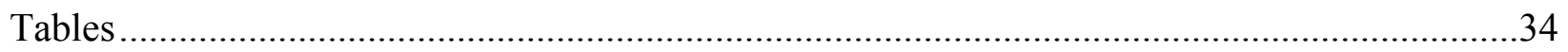

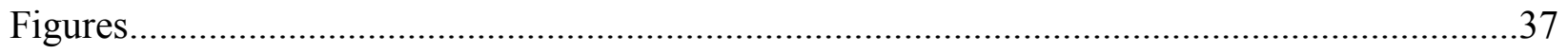

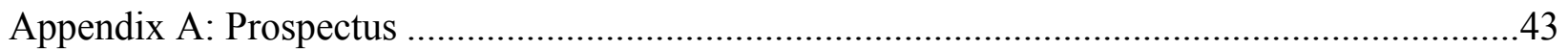

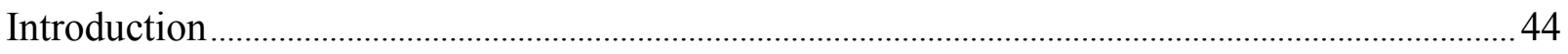

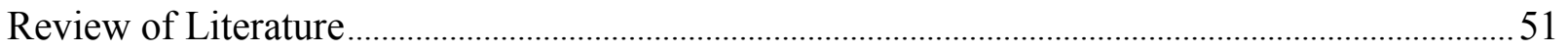

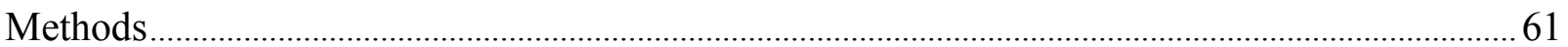

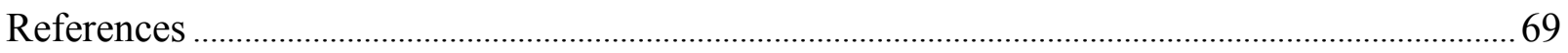

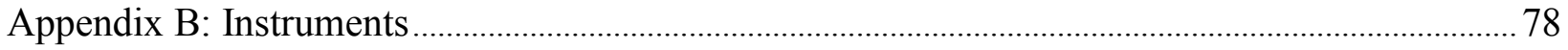

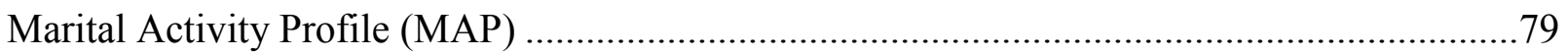

Fulfillment of Psychological Needs during Couple Leisure (FPNL) ...................................90

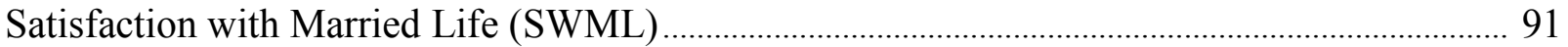




\section{List of Tables}

1. Descriptives for TCLS, FPNL, Autonomy, Competence, Relatedness, and MS ..................34

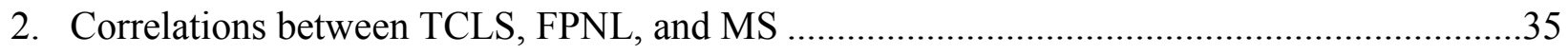

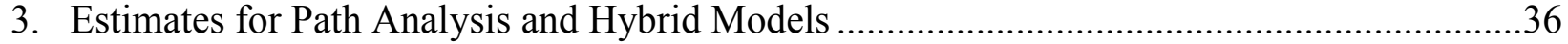




\section{List of Figures}

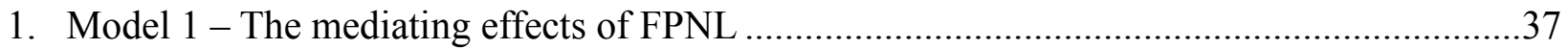

2. Models for the individual mediating effects of Autonomy (A), Competence (C), and

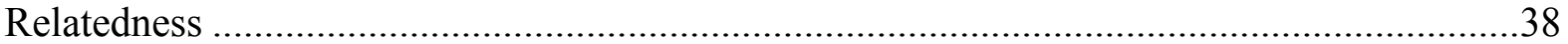

3. Model 5 -Autonomy (A), Competence (C), and Relatedness (R) influencing the mediating

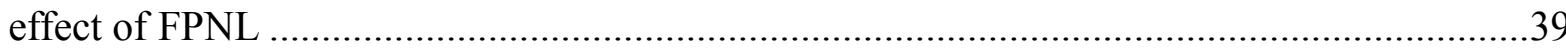

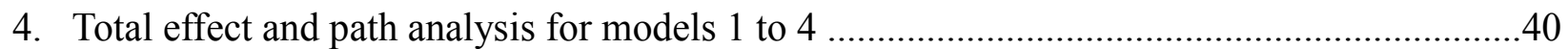

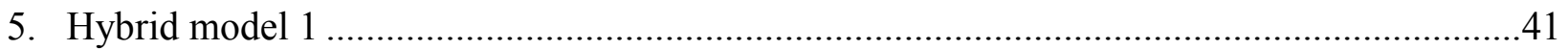

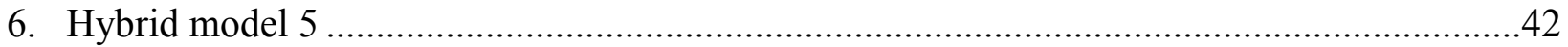


The Mediating Effects of Autonomy, Competence, and Relatedness During Couple Leisure on the Relationship Between Total Couple Leisure Satisfaction and Marital Satisfaction The rush of modern life is a significant factor contributing to unsatisfactory marital relationships (Cornelius, 2003; Kabeer, 2000, 2007; Schneider, Ainbinder, \& Csikszentmihalyi, 2004). Walking in the park, sitting down to talk, and other simple activities that couples once frequently engaged in during their leisure time seem to be gradually losing their availability and importance (Appleton \& Bohm, 2001). The battle to provide financial support for the family, the struggle of raising children, and the use of technological and media devices are some of the many competing forces a husband and wife face in their attempt to strengthen their relationship (Claxton \& Perry-Jenkins, 2008; Greenwood, Guner, Kocharkov, \& Santos, 2012).

Given these modern challenges to marital satisfaction, the need to strengthen marriages and families becomes clear and widely applicable. Research on the welfare of marriages has revealed significant findings related to the importance of couple leisure in maintaining and nourishing marital relationships (Berg, Trost, Schneider, \& Allison, 2001; Orthner, 1975). Studies have demonstrated that the amount of time spent on couple leisure and particularly the satisfaction level of those activities are powerful predictors of marriage quality (Ahlstrom, Lundberg, Zabriskie, Eggett, \& Lindsay, 2012; Crawford, Houts, Huston, \& George, 2002). Johnson, Zabriskie, and Hill (2006) further explained that satisfaction with home-based, common, and everyday leisure activities contributed more to increased marital satisfaction than novel, less frequent activities (e.g., travel, shows, and dinners at extravagant restaurants). Although these studies significantly clarified the relationship between couple leisure satisfaction and marital satisfaction, additional theoretical work is necessary to explain the association. 
Among the numerous social theories, self-determination theory (SDT) has provided a framework for examining marriage quality in several studies (Blais, Sabourin, Boucher, Vallerand, 1990; Gaine, \& La Guardia, 2009; Gaudreau, Fecteau, Perreault, 2010; Knee, Patrick, Vietor, Nanayakkara \& Neighbors, 2002; Weinstein, Hodgins, \& Ryan, 2010). Most of these studies, however, focus on spouses' motivational levels toward marriage or on the implications of autonomy orientation versus control orientation within close relationships. The important role of fulfilling the three psychological needs (a fundamental component of the SDT) and its implication in marital satisfaction has received little attention. The present study, then, proposes to contribute

to the published literature by using SDT — specifically the fulfillment of psychological needs —as a mechanism to better understand the previously established association between couple leisure satisfaction and marital satisfaction.

\section{Review of Literature}

\section{Marital Satisfaction}

The ever-growing need for strengthening the well-being of individuals and families has led scholars in marriage and family research to investigate marital satisfaction in depth (Bradbury, Fincham, \& Beach, 2000). The processes of forming and maintaining satisfied marital relationships, as well as preventing or alleviating divorce, provides the justification for studying marital satisfaction (Bradbury et al., 2000; Gorchoff, John, \& Helson, 2008; Lavner \& Bradbury, 2010; Rogers \& Amato, 1997).

A clear definition of marital satisfaction was given by Ward, Lundberg, Zabriskie, and Berrett (2009). They stated that marital satisfaction is “an individual's emotional state of being content with the interactions, experiences, and expectations of his or her married life" (p. 415). Other definitions have proposed that simply identifying positive elements within marital 
interactions, experiences, and expectations does not necessarily mean being content with the relationship (Bradbury et al., 2000). Similarly, perceiving negative elements may not be equal to marital dissatisfaction. Marital satisfaction occurs when positive elements outweigh negative elements; likewise, marital dissatisfaction occurs when negative elements outweigh positive elements (Bradbury et al., 2000).

Within the past decade, research has identified a variety of benefits related to satisfied marriages. Studies have found that being in a satisfied relationship diminishes negative health effects related to stressful workloads (Saxbe, Repetti, \& Nishina, 2008), improves marital disclosure (Slatcher, Robles, Repetti, \& Fellows, 2010), and positively impacts parental adaptation (Benson \& Kersh, 2011). In contrast, individuals in marriages marked by distress have a tendency to present less parenting quality (Sturge-Apple, Davies, \& Cummings, 2006), to have frequent disputations (Skowron, 2000), and higher cortisol levels which, over the long-term can produce negative health effects (Saxbe, Repetti, \& Graesch, 2011).

In addition to the above factors, researchers have identified at least five elements associated with the quality of marital relationships (Bradbury et al., 2000; Lavner \& Bradbury, 2010). First, personal traits such as depression (Mead, 2002; Gotlib, Lewinsohn, \& Seeley, 1998) and aggressiveness (Langer, Lawrence, \& Barry, 2008) have been found to negatively impact marital quality. Second, life stressors such as financial problems (Bradbury et al., 2000) and work stress (Schneider et al., 2004) are also negatively associated with marital quality (Neff \& Karney, 2007). Third, the way couples communicate and discuss conflicts has been another predictor of marital satisfaction (Rehman et al., 2011, p. 101). The fourth element presented here is the presence of children at home. Twenge, Campbell, and Foster (2003) demonstrated that even though the responsibilities attached to child caregiving may diminish marital satisfaction, couples can still 
strengthen their relationship while parenting by properly distributing parental duties and communicating in a positive manner (Claxton \& Perry-Jenkins, 2008).

Finally, scholars have highlighted the importance of spousal time for marital satisfaction (Appleton \& Bohm, 2001; Dew \& Wilcox, 2011; Gager \& Sanchez, 2003). Appleton and Bohm investigated tactics mid-life couples used to strengthen their marriages and indicated that simple actions such as stopping to smell the roses or "just sitting" together contributed to the quality of couples' relationships. Activities that include "the combination of free time and the expectation of preferred experience" as well as a "lack of obligation" and a "sense of opportunity" are commonly considered leisure experiences (Kleiber, 1999, p. 3). When these activities are participated in with a significant other, they are frequently referred to as "couple leisure" (Johnson et al., 2006). The present study seeks to further understand the relationship between couple leisure activities and marital satisfaction.

\section{Couple Leisure and Marital Satisfaction}

Research on the association between couple leisure and marital satisfaction has gained importance over past decades. Orthner (1975) analyzed the influence of three leisure activity patterns on marital satisfaction. The activities included the following: individual (with no communication or interaction between spouses), parallel (with minimal couple interaction or communication), and joint (high interaction and open communication). His findings indicated that, compared to individual and parallel activities, joint activities tended to present the most positive relationship toward marriage quality. Other studies also indicated spouses who engaged in leisure activities together presented higher levels of marital satisfaction (Claxton \& Perry-Jenkins, 2008; Holman \& Epperson, 1984; Orthner \& Mancini, 1991). Particularly, research has demonstrated couple leisure increases marital bonding and marital intimacy (Herridge, Shaw, \& Mannell, 2003), 
enhances couple communication (Holman \& Jacquart, 1988; Orthner, 1975), and decreases spouses' stress levels (Schneider et al., 2004).

In the past decade, studies have directly suggested that it is the satisfaction with couple leisure rather than simply the amount of time spent together in leisure that significantly contributed to relationship satisfaction (Berg et al., 2001; Crawford et al., 2002; Johnson et al., 2006). In fact, a longitudinal study conducted by Crawford et al. indicated that engagement in joint activities enjoyed only by husbands served as a detriment for wives' satisfaction with marriage. Ahlstrom et al. (2012) provided additional evidence by studying couples in which either one or both spouses played online games. They revealed that couples suffered marital distress when only one spouse engaged in this leisure activity. Spouses also suffered marital dissatisfaction when they participated together in online games but only one of them was satisfied with the activity. In contrast, higher levels of marital satisfaction were perceived when both spouses played online games and both were satisfied with the activity.

Apart from the significance of the findings presented above, little theoretical work has been done in order to explain the association between satisfaction with couple leisure and marital satisfaction. Johnson et al. (2006) utilized the Core and Balance framework to specifically examine the contribution of the type of couple leisure activities, amount of time spent on them, and satisfaction with couple leisure to overall marital satisfaction. Core couple leisure activities included the type of leisure that occurred on a regular basis and mostly within or around the couple's residence. Examples of core couple leisure include eating together, doing the dishes together, watching television together, and going on walks together. Balance couple leisure activities referred to the type of leisure that is less common, less frequent, and mostly not homebased, such as vacations, camping, fishing, and attending theatrical performances (Zabriskie \& 
McCormick, 2001). Johnson et al. revealed that, compared to satisfaction with balance couple activities, satisfaction with core couple leisure contributed the most to the explanation of increased levels of marital satisfaction. Despite these significant findings, Johnson et al. recognized that their study sample size of 48 couples was not reflective enough; therefore, they recommended reproducing their findings with a larger and more geographically diverse sample.

In response to the aforementioned recommendation, two studies analyzed the relationship between couple leisure satisfaction and marital satisfaction using a sample of 1,187 couples across the United States (Williamson, Zabriskie, Fellingham, Ward, \& Lundberg, 2013; Ward, Barney, Lundberg, \& Zabriskie, 2013). Both studies reaffirmed Johnson et al., indicating that, in the context of leisure, core couple leisure satisfaction was the strongest single predictor of marital satisfaction. Ward et al. revealed, however, that core couple leisure satisfaction and balance couple leisure satisfaction were strongly correlated $(r=.886)$. Because the latent variables' correlation was stronger than .80 (Kline, 2005), these two variables were combined into a new variable, total couple leisure satisfaction. This new variable suggested that although balance couple leisure satisfaction was a weaker contributor to overall marital satisfaction, the inclusion of balance activities would still increase levels of marital satisfaction, indicating the need of both core and balance leisure satisfaction in order to reach higher levels of marital satisfaction (Zabriskie \& McCormick, 2001). Thus, Ward et al. added to previous research by specifically identifying total couple leisure satisfaction as a consistent, strong predictor of marital satisfaction.

Although these studies (Johnson et al., 2006; Ward et al., 2013; Williamson et al., 2013) offered additional understanding regarding the relationship between couple leisure and marital satisfaction, particularly identifying the important role of total couple leisure satisfaction, further theoretical examination is needed to understand why the element of satisfaction within couple 
leisure is so highly associated with marital satisfaction. The present study employs selfdetermination theory (SDT) as a mechanism, or explanatory framework, to further understand the association between total couple leisure satisfaction and marital satisfaction.

\section{Self-Determination Theory}

Several studies on marital relationships have used SDT as a theoretical foundation (Blais et al., 1990; Gaine, \& La Guardia, 2009; Gaudreau et al., 2010; Knee et al., 2002; Weinstein et al., 2010). The fundamental idea of SDT consists of the principles associated with individuals' motivational levels (Ryan \& Deci, 2000). Deci and Ryan (2000) explained that motivational levels can vary from amotivation and extrinsic motivation to intrinsic motivation. Intrinsically motivated behaviors involve active engagement in tasks solely for spontaneous enjoyment and personal satisfaction. In contrast, extrinsically motivated behaviors have the expectation of specific outcomes, such as obtaining rewards and avoiding punishments (Deci \& Ryan). SDT claims that intrinsic motivation is supported and maintained through the fulfillment of three basic psychological needs: autonomy, competence, and relatedness (Ryan \& Deci, 2007; Lundberg, 2009).

It is important to distinguish each psychological need, as the needs individually play a specific role in the development of intrinsic motivation. As stated by Gagne and Deci (2005), "autonomy involves acting with a sense of volition and having the experience of choice" (p. 333). In a simple description, autonomy is the opportunity to be in control of or the source of one's behavior. Competence refers to an individual's ability to perform tasks effectively. The need for competence leads people to seek challenges that match their abilities and to either maintain or enhance those skills through involvement in activity. According to Reis, Sheldon, Gable, Roscoe, and Ryan (2000), "the need for relatedness pertains to feeling that one is close and connected to 
significant others" (p. 420). Fulfillment of these three psychological needs is associated not only to intrinsic motivation but also to personal growth, integrity, well-being (Deci \& Ryan, 2000), and marital satisfaction (La Guardia, Ryan, Couchman, \& Deci, 2000; La Guardia \& Patrick, 2008; Patrick, Knee, Canevello, \& Lonsbary, 2007).

\section{The relationship between fulfillment of psychological needs and marital satisfaction.}

Most studies linking SDT and marital satisfaction focus on the individuals' motivational levels in their marital relationships or on the implications of autonomy orientation versus control orientation within close relationships (Blais et al., 1990; Gaine, \& La Guardia, 2009; Gaudreau et al., 2010; Knee et al., 2002; Weinstein et al., 2010). These studies, however, left unmentioned the important role of fulfilling the three psychological needs. Few researchers have indicated that fulfillment of autonomy, competence, and relatedness within close relationships has important implications for relationship satisfaction (La Guardia et al., 2000; La Guardia \& Patrick, 2008). Patrick et al. (2007), in conducting three separate studies on the association between fulfillment of the three psychological needs and well-being among couples, found that the more one perceived needs being fulfilled by his or her partner, the greater was the relationship satisfaction and well-being, while perceived conflict and defensive responses to conflict decreased. La Guardia and Patrick explained that in a close relationship, a needs-supportive individual engages in efforts to understand his or her partner's interests, preferences, and perspectives (autonomy); considers the partner's capacities and limitations (competence); and demonstrates continual care and diligent involvement toward the partner (relatedness). Despite these significant findings, additional clarification is necessary in applying the fulfillment of psychological needs within specific areas of marriage (e.g., professional aspirations and raising children) and its impacts on marital satisfaction. 
The present study then proposes to specifically consider fulfillment of psychological needs during couple leisure and investigate its influence on marital satisfaction.

\section{Using fulfillment of psychological needs to understand the link between total couple}

leisure satisfaction and marital satisfaction. Family science literature has documented significant associations between fulfillment of psychological needs during couple leisure and relationship satisfaction (Baldwin, Ellis, \& Baldwin, 1999; Goff, Fick, \& Oppliger, 1997; Goodsell \& Harris, 2011; Ricard, Beaudry, \& Pelletier, 2012). These studies, however, focused mostly on the fulfillment of the psychological need of autonomy, which is frequently mentioned as “autonomy support” or simply "support” (Deci \& Ryan, 1987). For example, Baldwin et al. investigated the relationship between leisure support and marital satisfaction among married couples where at least one spouse runs frequently. Their results contradicted Orthner's (1975) conclusion that individual leisure was negatively associated with marital satisfaction. Baldwin et al. reported that when spouses supported partner's individual leisure (running), marital satisfaction was higher than when there was no support for individual leisure, and it was comparable to engagement in meaningful joint recreation. Although the study didn't specifically involve each of the three psychological needs, Baldwin et al. drew an important conclusion regarding leisure support. They suggested that the presence of support in leisure activities seemed to be more significant in determining satisfied marriages than the participation in shared or joint activities.

Recent studies on spouses' motivational support in leisure activities revealed similar implications toward relationship satisfaction (Goff et al., 1997; Ricard et al., 2012). Further investigation into the influence of serious running on the quality of marital relationships indicated that "although many non-runners were supportive of their spouses' running, this effect was amplified when both spouses shared an interest in running" (Goodsell \& Harris, 2011, p. 89). 
Since people tend to choose to participate in activities they feel most interested in and satisfied with (Kleiber, 1999; Shaw, 1985), Goodsell and Harris's findings suggested that runners felt more supported by their spouses when they ran together and felt mutually satisfied with the activity. Their study also revealed that the benefits experienced by supportive spouses (both runners and non-runners) of runners included health and wellness, stress relief, meaningful ties, and stronger relationships. Otherwise stated, these findings suggested that combining support in leisure and joint participation would result in higher levels of marital satisfaction. While Goodsell and Harris's study contributed to the marital satisfaction body of research by finding associations with leisure support, it was not generalizable across populations because of its qualitative nature. In addition, the idea of leisure support Goodsell and Harris used in their study referred only to the psychological need of autonomy, as it occurred in Baldwin et al.'s study. Both studies left unexplored the importance of fulfilling the three psychological needs in couple leisure and how that fulfillment may be associated with satisfied marriages.

In general, the influence of autonomy, competence, and relatedness have been separately analyzed in association to relationship functioning and well-being (La Guardia \& Patrick, 2008; Patrick et al., 2007; Reis et al., 2000). Patrick et al. revealed that "the fulfillment of each need individually predicted both individual and relationship well-being, with relatedness being the strongest unique predictor of relationship outcomes" (p. 434). They supposed that, although autonomy and competence have been traditionally reported as the most influential psychological need in achieving intrinsic motivation, relatedness plays a particularly important role in the context of close relationships. The present study, then, proposes to explore the significance of fulfilling each psychological need and its mediating effect on the relationship between couple leisure satisfaction and marital satisfaction. 
As previously stated, scholars have documented the positive association between couple leisure satisfaction and marital satisfaction (Berg et al., 2001; Crawford et al., 2002; Johnson et al., 2006). Ward et al. (2013) clearly reported that total couple leisure satisfaction is a strong positive indicator of marital satisfaction. The present study, then, proposes to add to this line of research by expanding the idea of need support in leisure (Goodsell \& Harris, 2011; Patrick et al, 2007) using the fulfillment of psychological needs (autonomy, competence, and relatedness) during couple leisure as mediators between total couple leisure satisfaction and marital satisfaction.

\section{Methods}

\section{Data Collection Procedures}

The present study is an analysis of additional data collected during 2007 (Ward et al., 2009). Data was collected via Survey Sampling International using its data base of over two million U.S. households. Online data collection versus paper and pencil surveys have yielded similar results, demonstrating that there is not a significant difference between these two data collection procedures (Ward, Clark, Zabriskie, \& Morris, 2012). An e-mail with a link to the online questionnaire in Qualtrics was distributed to Survey Samplings International's data base until it reached the targeted sample of 1,200 couples. Couples were asked to independently answer the questionnaire in order to encourage authentic responses. After successfully completing the entire questionnaire, participating couples were entered into a drawing to receive a quarterly cash prize.

\section{Sample}

From the initial 1,226 couples, 39 were excluded due to unfinished questionnaires or extreme outliers in couple behavior (e.g., reporting 20 hours of family dinner every day of the week). In addition, partners' responses of each of the 1,187 couples were compared to ensure 
compatibility of answers. Couples that demonstrated very different answers on the joint participation items were eliminated from the analysis.

Respondents of the current sample were compared via residency of four US regions: Northeast (23.8\%), Midwest (24.6\%), South (34.5\%), and West (17.2\%). The mean age for men was $52.0(\mathrm{SD}=13.80)$ and the mean age for women was $39.5(\mathrm{SD}=13.25)$. The mean annual household income ranged from less than $\$ 10,000$ to over $\$ 150,000$, with both a mean and mode of $\$ 40,000$ to $\$ 49,999$. Eighty-nine percent of the sample reported being currently married, and $57 \%$ percent reported being previously divorced. The majority of respondents were white $(2,242$ or 91.8\%) followed by Black ( 88 or 3.6\%), Hispanic (52 or $2.1 \%$ ), Asian (26 or 1.1\%), Native American (27 or 1.1\%), and Pacific Islander (6 or .25\%). Forty-seven of the couples reported being in a same sex relationship, and of these relationships, 32 of the relationships were female.

\section{Instrumentation}

Data were collected using the following instruments: (a) a 15-item Couple Leisure Satisfaction Scale (CLSS) that is embedded in the Marital Activity Profile (MAP), which measures satisfaction with core and balance couple leisure involvement (Johnson et al., 2006); (b) a nineitem Fulfillment of Psychological Needs during Couple Leisure (FPNL) scale that measures the fulfillment of autonomy, competence, and relatedness during couple leisure. The FPNL is a revised version of Need Satisfaction with Spouse Scale (NSSS) (LaGuardia et al., 2000); (c) a five-item Satisfaction with Married Life scale (SWML, Ward et al., 2009); and (d) relevant sociodemographic data.

Couple Leisure Satisfaction Scale (CLSS). The Couple Leisure Satisfaction Scale measures total couple leisure satisfaction (TCLS) and is embedded in the MAP. The MAP measures couple leisure involvement based on the Core \& Balance family leisure framework 
(Zabriskie, 2000) and contains questions on both core (e.g., home-based TV/video-watching together, regular communication, and playing games together) and balance (e.g., community based events, outdoor activities, adventure activities, and travel together) couple leisure, and has demonstrated acceptable psychometric properties (Johnson, et al., 2006). Following each of the 15 items measuring couple leisure involvement is an item that asks how satisfied the respondent is with their involvement or lack of involvement in the previous activity category. Recent research found that core couple leisure satisfaction and balance couple leisure satisfaction were highly correlated (.886) and were therefore combined into a new variable: total marital leisure satisfaction (Ward et al., 2009). Ward et al. also found that the balance couple leisure satisfaction estimates did not significantly contribute to total couple leisure satisfaction and were trimmed from the model. In addition, two items on core couple leisure satisfaction (home-based activities and religious/spiritual activities) were not significant, due to low participation rates; therefore, these items were also eliminated. The CLSS, then, is composed of 6 items in which responses are rated on a Likert-type scale with scores ranging from 1 (very dissatisfied) to 5 (very satisfied). Scores for total couple leisure satisfaction are scored by summing all items. While internal consistency for total couple leisure satisfaction has not been reported in the literature, model fit for core couple leisure satisfaction and balance couple leisure satisfaction were reported in Ward et al. (2013) and they fall within acceptable ranges. Model fit for total couple leisure satisfaction model fit was first reported in the literature in the results section of the present study.

Fulfillment of Psychological Needs during Couple Leisure (FPNL). The mediating variables, autonomy, competence, and relatedness, were measured through the FPNL scale, a modified version of the nine-item Need Satisfaction with Spouse Scale (NSSS) (LaGuardia et al., 2000). While NSSS measures the fulfillment of each of the three basic psychological needs during 
interaction with one's spouse, FPNL focuses specifically on couple leisure. Thus, the original words "When I am with my spouse" in the NSSS were substituted with "During our recreation participation" on the FPNL.

Each of the three psychological needs contained three items on the questionnaire. Examples of autonomy, competence, and relatedness items are respectively "During our recreation participation, I feel like a competent person," "During our recreation participation, I feel free to be who I am," and "During our recreation participation, I often feel loved and cared about." Participants rated on a 7-point Likert scale $(1=$ not very true at all, $7=$ very true $)$ how well their psychological needs were met during couple leisure. Each psychological need score varied from 3 to 21, and the total score (FPNL) was obtained through the sum of all items ranging from 9 to 63 . La Guardia et al. (2000) reported a Cronbach's Alpha of .88 for NSSS.

Satisfaction with Married Life (SWML). The dependent variable, marital satisfaction (MS), was measured using the five-item scale SWML (Ward et al., 2009). The SWML scale is a modified version of the Satisfaction with Life Scale (Diener, Emmons, Larsen, \& Griffin, 1985), where the word "life" was replaced by "married life." A sample item is "I am satisfied with my married life" (Johnson et al., 2006). Participants rated each of the five items on a 7-point Likerttype scale $(1=$ strongly disagree, 7 = strongly agree $)$. The items were then summed producing a satisfaction with married life score ranging from 5 to 35 . The higher the score, the greater the satisfaction with married life. Previous Cronbach's alpha of .92 and .96 were respectively reported by Johnson et al. and Ward et al.

Demographics. The following categories were included in the demographic questionnaire in order to examine underlying characteristics of the sample: (a) gender, (b) age, (c) ethnicity, (d) 
previous marital history, and (e) income (see Appendix A). These items were used to describe the sample.

\section{Data Analysis}

Structural equation modeling (SEM) in Amos 20.0 was used in order to explore the mediating effects of Fulfillment of Psychological Needs during Couple Leisure (FPNL) on the relationship between Total Couple Leisure Satisfaction (TCLS) and marital satisfaction as represented in the Satisfaction with Married Life Scale (SWML). MacKinnon, Fairchild, and Fritz (2007) described mediation as "the addition of a third variable to [the] $\mathrm{X} \rightarrow \mathrm{Y}$ relation, whereby $\mathrm{X}$ causes the mediator, $M$, and $M$ causes $Y$, so $X \rightarrow M \rightarrow Y$ ” (p. 595). Otherwise stated, mediation is the inclusion of a third variable that, when included in a regression model together with the independent variable (IV) and dependent variable (DV) significantly reduces the correlation between IV and DV (Baron \& Kenny, 1986). An additional explanation for mediation is that a direct effect is found when $\mathrm{X}$ is significantly correlated with Y while an indirect effect (also called mediated effect) occurs when the relationship between $\mathrm{X}$ and $\mathrm{Y}$ is significantly reduced by the inclusion of a mediating factor (MacKinnon et al.; MacKinnon, Lockwood, Hoffman, West, \& Sheets, 2002). Therefore, this study explored Total Couple Leisure Satisfaction (X) and its relationship to Satisfaction with Married Life (Y) as mediated by the Fulfillment of Psychological Needs during Couple Leisure (M) (see Figure 1) and tested the indirect effect of FPNL using the Sobel test, as indicated in Baron and Kenny. The purpose of the Sobel test is to determine if the relationship between the IV and DV has been significantly reduced after including the mediator variable (MacKinnon et al., 2002).

The present study implemented Barron and Kenny's four-step approach to mediation (Baron \& Kenny, 1986; Bedini, Gladwell, Dudley, \& Clancy, 2011). First, there must be a 
significant relationship between TCLS to SWML, path c. Second, there must be a significant relationship between TCLS and FPNL, path a. Third, FPNL must be significantly related to SWML when TCLS is also predicting SWML, path $\mathrm{b}$. Fourth, the relationship between TCLS and SWML, path $\mathrm{c}^{\prime}$ must be smaller after the inclusion of FPNL. If $\mathrm{c}^{\prime}$ is zero, then the relationship between TCLS and SWML has total mediation through FPNL. If $\mathrm{c}^{\prime}$ is greater than zero, but less than $\mathrm{c}$, the relationship between TCLS and SWML is partially mediated by FPNL.

The model presented above (see Figure 1) is the first step of the analysis. It covers only a general perspective of the mediating effect of psychological needs. In order to investigate the influence of each psychological need separately, four additional models were analyzed. Three models examined each psychological need individually as a mediator on the relationship between TCLS and SWML (see Figure 2). This step provided specific information on the significance and strength of the mediating effect of autonomy, competence, and relatedness. The third and last step of the analysis examined the fifth model and investigated the strength of each psychological need in predicting FPNL (see Figure 3). Confirmatory factor analysis (CFA) for TCLS, FPNL, and SWML were used to test the adequacy of each measurement model. The analysis of all five models included a path analysis, testing the measurement models, then combined the path diagrams to the measurement models, resulting in the hybrid models (Kline, 2005).

Evaluation of goodness of fit was examined through three conservative model fit indices (Kline, 2005). First, the comparative fit index (CFI) considered the model's absolute or parsimonious fit relative to the null or hypothetical model. An index score of .95 or greater was desired. Second, the root mean square error of the approximation (RMSEA) was considered to assess fit based on the magnitude of the residuals. An index score of .08 or less was desired. Third, the standardized root mean square residual (SRMR) was used to measure the standardized 
differences between the observed covariance and the predicted covariance. A value of less than .08 is considered an appropriate fit.

\section{Results}

\section{Variable Statistics and Correlations}

The means, standard deviations, and ranges for all measured variables were reported (see Table 1). In order to address the issue of multicollinearity, a correlation matrix was created for Total Couple Leisure Satisfaction (TCLS), Fulfillment of Psychological Needs during Couple Leisure (FPNL), and Satisfaction with Married Life (SWML) (see Table 2). These variables, as expected, were strongly positively correlated. While these correlations were strongly positive, they did not meet the criteria outlined by Kline (2005) to be combined into one variable. Each observed variable provided enough unique and significant contribution to be treated separately.

\section{Path Analysis}

Paths of a, b, c, and c' were used to test for mediation (Baron \& Kenny, 1986) in each of the four path analysis models (see Figure 1). Before the mediating effect was introduced to the models, the standardized total effect of TCLS to SWML (path c) was .648. In accordance with Baron and Kenny, when the mediating effect was included (as in paths a and b), the resulting mediating effect (path $\mathrm{c}^{\prime}$ ) must be less than the direct effect (path c). The beta weight estimates for paths $\mathrm{a}, \mathrm{b}, \mathrm{c}$ and $\mathrm{c}^{\prime}$ in the four models were significant (see Table 3). When all three psychological needs were combined into the variable FPNL (Model 1), path analysis explained 52\% of the variance in SWML. When each psychological need was tested separately as mediators (Models 2 to 4), the model containing relatedness presented the greatest standardized indirect effect toward SWML (.297). Path analysis of Models 2 to 4 explained respectively $47.90 \%, 45.80 \%$, and $59.10 \%$ of the variance of SWML, demonstrating that relatedness was the strongest single 
mediator on the relationship between TCLS and SWML. Furthermore, when testing for significance of mediation, the Sobel Test was significant for all four models (see Table 3).

\section{Measurement Model}

A CFA was used to test the measurement model for TCLS, FPNL, and SWML. The facture structure of TCLS was modeled after the Ward et al. (2013) manuscript. The contributing indicators were around core satisfaction and had standardized regression weights ranging from .603 for satisfaction in meals eaten at home to .789 for games played as a couple at home. Model fit indices for TCLS were acceptable $(\mathrm{CFI}=.999$; RMSEA $=.022$, CI [90\%] .00 to .04 ; SRMR $=$ .007). The CFA of FPNL included all of the indicators for need fulfillment as outlined in the Need Satisfaction with Spouse Scale (LaGuardia et al., 2000). The modification indices suggested correlating the indicator errors for the individual items that contributed to autonomy, competence, and relatedness respectively. The standardized regression weights ranged from .471 for "During our recreation participation, I often feel inadequate or incompetent" to .852 for "During our recreation participation, I feel free to be who I am.” Model fit indices for FPNL were acceptable $(\mathrm{CFI}=.989 ; \mathrm{RMSEA}=.061, \mathrm{CI}[90 \%] .053$ to.069; SRMR $=.017)$. The CFA of SWML included the five indicators as outlined by Ward et al. (2009). The modification indices suggested correlating the errors between several of the items. The standardized regression weights ranged from .827 for "If I could live my married life over, I would change almost nothing" to .954 for "The conditions of my married life are excellent" (Johnson et al., 2006; Ward et al., 2009). Model fit indices for SWML were acceptable $(\mathrm{CFI}=.999 ; \mathrm{RMSEA}=.083$, CI [90\%].051 to .119; SRMR $=.004)$. 


\section{Hybrid Models}

The individual measurement models were combined with the path analyses to test five different hybrid models (Kline, 2005). The first hybrid model tested was the mediation model between TCLS and SWML using FPNL as the mediator (see Figure 5). Partial mediation was present with an indirect effect of .437 and a Sobel test of 22.775 (see Table 3). In addition, hybrid model 1 explained $45 \%$ of the variance of SWML.

The next three models tested included the individual factors of autonomy, competence, and relatedness as mediators. Each of these models met the criteria outlined by Baron and Kenny (1986) for partial mediation. As occurred in the path analysis models, testing each psychological need separately demonstrated that relatedness was the strongest single mediator on the correlation between TCLS and SWML (Model 4). Hybrid Model 4 explained 64.4\% of the variance of SWML, with an indirect effect of .578 and Sobel test of 23.790 (see Table 3).

Since partial mediation was present for autonomy, competence, and relatedness, these variables were used as predictor variables in Hybrid Model 5 (see Figure 6) to better understand their influence on the mediating effect of FPNL. Among the three psychological needs, relatedness had the strongest beta weight $(\beta=.995)$, followed by autonomy $(\beta=.749)$, and then competence $(\beta=.634)$.

Hybrid Model 5 explained $64.3 \%$ of the variance of SWML, with an indirect effect of .303 and Sobel test of 16.685 (Table 3). This model uniquely presented a stronger direct effect than the indirect effect, indicating the combination of autonomy, relatedness, and competency didn't have as strong a mediating influence as the individual variables. The amount of variance explained in SWML, however, is almost identical to Model 4 due to the presence of relatedness in the model. 


\section{Models' Fit}

Conservative model fit indices for Hybrid Models 1 to 4 yielded acceptable values. (See Table 3). Goodness of fit for hybrid model 5 was acceptable $(\mathrm{CFI}=.989$; RMSEA $=.045, \mathrm{CI}$ [90\%] .040 to $.049 ;$ SRMR $=.029)$. Hoetler's fit index indicated the model would still have been significant with 543 participants, meaning the model's significance was not driven by the large sample size in this study.

\section{Discussion}

The findings of this study highlighted the mediating effects of autonomy, competence, and relatedness on the relationship between Total Couple Leisure Satisfaction (TCLS) and Satisfaction with Married Life (SWML). Data analysis revealed that Fulfillment of Psychological Needs during Couple Leisure (FPNL) is a significant mediator on the relationship between TCLS and SWML, confirming the hypothesis that self-determination theory (SDT) is a satisfactory theory to further understand the relationship between couple leisure satisfaction and marital satisfaction. Furthermore, comparing the mediating strength of each psychological need, relatedness was the strongest single mediator between TCLS and SWML. This finding regarding relatedness confirms the previous research of Patrick et al. (2007) indicating that, in the context of human relationships, relatedness is particularly important in relationship functioning and well-being.

\section{The Relevance of Self-Determination Theory}

The present study identified SDT as a mechanism to further understand the relationship between TCLS and SWML. This finding is in response to previous recommendations in the literature to identify stronger theoretical foundations regarding the association between couple leisure satisfaction and marital satisfaction (Johnson et al., 2006; Ward et al, 2013). SDT proposes that individuals tend to achieve well-being and satisfaction in closes relationship when the basic 
psychological needs of autonomy, competence, and relatedness are fulfilled (La Guardia et al., 2000; La Guardia \& Patrick, 2008). The current study applied SDT into a specific area of marriage - couple leisure — by using a nine-item questionnaire (FPNL) and by testing FPNL as a mediator. Model 1 tested the mediating effects of FPNL when this mediator consisted of the scores of all three needs combined into a total score. The analysis of this model demonstrated that FPNL was a significant mediator on the relationship between TCLS and SWML, confirming the initial hypothesis that SDT, and the satisfaction of psychological needs, may be an appropriate theory to better understand the mechanisms underlying the existing relationship between couple leisure satisfaction and marital satisfaction. While most studies on relationship satisfaction using SDT focus on individuals' motivational levels or on the implications of autonomy orientation versus control orientation (Blais et al.,1990; Gaine, \& La Guardia, 2009; Gaudreau et al., 2010; Knee et al., 2002; Weinstein et al., 2010), the present research complements a smaller number of studies that identify the fulfillment of psychological needs as an important indicator of marital satisfaction (Patrick et al., 2007; Reis et al., 2000).

\section{The Mediating Effects of Autonomy, Competence, and Relatedness}

Until this point, few studies have attempted to examine the individual influence of each psychological need on close relationships and couple behavior (La Guardia \& Patrick, 2008; Patrick et al., 2007; Reis et al., 2000). In order to test the mediating effects of autonomy, competence, and relatedness separately, three additional models were created (Model 2 Autonomy; Model 3 - Competence; Model 4 - Relatedness). The analysis of these three models revealed that each psychological need significantly mediated the relationship between TCLS and SWML. La Guardia and Patrick identified that well-being in a close relationship is more likely to be promoted when partners are supportive of their companion's interests, preferences, and 
perspectives (suggesting the fulfillment of autonomy), by providing clear, consistent, and reasonable expectations and structure (suggesting the fulfillment of competence), and by continually conveying interest and care (suggesting the fulfillment of relatedness). Applying these concepts to couple leisure settings, individuals should be attentive to their spouses' psychological needs while they spend time together in order to strengthen their marriage quality.

To further illustrate the concept of satisfying each psychological need during couple leisure, the following examples are provided. If spouses attempt to support their partner's autonomy during couple leisure, they could alternate turns in choosing the activities they participate in together, while keeping in mind that satisfaction on the part of both individuals is important. This would provide more choice and equivalent opportunities to fulfill personal interests for each spouse. It is important, however, to be frequently involved in activities where both partners feel enjoyment and satisfaction (Ahlstrom et al., 2012; Johnson et al., 2006). Furthermore, in order to fulfill the need for competence, couples could engage in activities together that provide enough challenge for both spouses, or modify activity components so that appropriate levels of challenge are available to individuals with different skill sets, while still participating together. Thus, the sensation of boredom can be minimized, while still providing opportunities for excitement, pleasure, and growth during a couple leisure experience. The importance of fulfilling the need for relatedness will be expanded on the next section.

\section{The Predominance of Relatedness in Reflecting the Mediating Effect of FPNL}

Finally, relatedness consistently appeared as the strongest single mediator when compared with autonomy, competence, and FPNL as a whole. Part of the analytical process required the creation of Model 5 in order to test the strength of autonomy, competence, and relatedness in the mediating effect of FPNL. The analysis of this last model resulted in a significant mediating 
effect. Not surprisingly, relatedness nearly perfectly reflected FPNL, while the other two psychological needs presented lower estimates, reemphasizing the particular strength of relatedness in mediating TCLS and SWML. This result reaffirmed the finding of Patrick et al. (2007) that "although each of the needs contributed in different ways to indicators of individual well-being, relatedness was the strongest unique predictor of relationship functioning and wellbeing" (p. 452). Patrick et al. also declared that most studies using SDT point toward autonomy and competence as the most powerful influences on intrinsic motivation and well-being. In the context of close relationships, however, relatedness becomes the focal influence for the achievement of relationship functioning and satisfaction. The current research resulted in similar findings through the predominance of relatedness over autonomy and competence in reflecting the mediating effect of FPNL. Further research, however, is still needed to clarify the preponderance of relatedness in the context of close relationships.

In the present study, the relatedness finding suggested that couples tend to feel satisfied with their leisure activities and with their overall marriage quality when spouses were attentive and caring with each other during the time they spent together. In a practical manner, spouses would be supportive of their partner's need for relatedness during couple leisure by focusing their attention on the partner's well-being instead of seeking other specific outcomes (e.g., win the game, show superiority in personal opinions and abilities, criticize partner's choices or performance). This attitude potentially creates an environment where spouses may feel important, cared for, and encouraged while feelings of neglectfulness, insensitivity, and enmity would be minimized.

Interestingly, the fulfillment of relatedness may also have a direct or indirect impact on the subsequent fulfillment of autonomy and competence. While these relationships require further 
testing, it seems reasonable that when continual care and diligent involvement (relatedness) are present, spouses may feel that their perspectives (autonomy) and capacities (competence) are more valued (La Guardia \& Patrick, 2008; Patrick et al., 2007). These concepts are applicable whether occurring during couple leisure or in other day-to-day marital interactions. Therefore, in order to achieve higher levels of leisure satisfaction and associated marital satisfaction, couples should focus their efforts on fulfilling partners' psychological needs, particularly keeping in mind the predominance of relatedness.

\section{Limitations and Future Recommendations}

Despite the significant findings, there are several limitations to the current study. First, further investigation is still necessary to understand why relatedness plays a stronger effect on overall need fulfillment when compared with autonomy and competence in the context of couple leisure. Studies using longitudinal data collection procedures or experimental designs would provide more clarity in this area of research. Second, while the study's focus was on a theoretical process, the analysis could not fully account for the shared dependence of spouses' scores. Now that a theoretical foundation has been established, a next step in this line of research may be to consider an actor-partner interdependence model (APIM) (Cook \& Kenny, 2005), a methodology used for measuring bidirectional effects in interpersonal relationships. Third, the present study used a correlational strategy and, therefore, has limited potential in understanding possible causal relationships between variables.

Another limitation of this research pertains to the uneven characteristics of the sample. Again, while the intent of this study was primarily theoretical, future research should seek samples more representative of participants from differing ethnicities within the United States (European Americans, African Americans, Latin Americans). 
Lastly, it is important to consider the questionnaire used to measure Fulfillment of Psychological Needs during Couple Leisure (FPNL). Additional testing and modification of the scale is warranted. Likewise, the role of other influential variables such as personality traits, life stressors, and the presence or absence of children in the home should be carefully considered in light of marital satisfaction (Bradbury et al., 2000; Twenge et al., 2003).

\section{Conclusion}

In summary, this study highlighted the importance of self-determination theory (SDT) in understanding the relationship between Total Couple Leisure Satisfaction (TCLS) and Satisfaction with Married Life (SWML) through the Fulfillment of Psychological Needs during Couple Leisure (FPNL). Likewise, the results demonstrated the significance of the mediating effects of autonomy, competence, and particularly relatedness in the association between TCLS and SWML.

The most interesting finding was the preponderance of relatedness over autonomy and competence in reflecting the mediating effect of FPNL. This contributes to the body of literature by identifying the important role of relatedness in promoting well-being in the couple leisure context, while autonomy and competence are most typically discussed as the key variables in predicting intrinsic motivation and well-being in other contexts, such as sports and work. In simple yet profound ways, the results of this study suggest that the key issue in explaining the relationship between couple leisure satisfaction and marital satisfaction is the presence of genuine care, sincere interest, and a sense of closeness expressed between couples during their shared leisure moments. 


\section{References}

Ahlstrom, M., Lundberg, N. R., Zabriskie, R., Eggett, D., \& Lindsay, G. B. (2012). Me, my spouse, and my avatar: The relationship between marital satisfaction and playing massively multiplayer online role-playing games (MMORPGs). Journal of Leisure Research, 44(1), $1-22$.

Appleton, C., \& Bohm, E. (2001). Partners in passage: The experience of marriage in mid-life. Journal of Phenomenological Psychology, 32(1), 41-70.

Baldwin, J. H., Ellis, G. D., \& Baldwin, B. M. (1999). Marital satisfaction: An examination of its relationship to spouse support and congruence of commitment among runners. Leisure Sciences, 21(2), 117-131.

Baron, R. M., \& Kenny, D. A. (1986). The moderator-mediator variable distinction in social psychological research: Conceptual, strategic, and statistical considerations. Journal of Personality and Social Psychology, 51(6), 1173-1182.

Bedini, L. A., Gladwell, N. J., Dudley, W. N., \& Clancy, E. J. (2011). Mediation analysis of leisure, perceived stress, and quality of life in informal caregivers. Journal of Leisure Research, 43(2), 153-175.

Benson, P. R., \& Kersh, J. (2011). Marital quality and psychological adjustment among mothers of children with ASD: Cross-sectional and longitudinal relationships. Journal of Autism Developmental Disorders, 41(12), 1675-1685.

Berg, E. C., Trost, M., Schneider, I. E., \& Allison, M. T. (2001). Dyadic exploration of the relationship of leisure satisfaction, leisure time, and gender to relationship satisfaction. Leisure Sciences, 23(1), 35-46. 
Blais, M. R., Sabourin, S., Boucher, C., \& Vallerand, R. J. (1990). Toward a motivational model of couple happiness. Journal of Personality and Social Psychology, 59(5), 1021-1031.

Bradbury, T. N., Fincham, F. D., \& Beach, S. R. H. (2000). Research on the nature and determinants of marital satisfaction: A Decade in review. Journal of Marriage and Family, 62(4), 964-980.

Claxton, A., \& Perry-Jenkins, M. P. (2008). No fun anymore: Leisure and marital quality across the transition to parenthood. Journal of Marriage and Family, 70(1), 28-43.

Cook, W. L., \& Kenny, D. A. (2005). The Actor-Partner Interdependence Model: A model of bidirectional effects in developmental studies. International Journal of Behavioral Development, 29 (2), 101-109.

Cornelius, T. J. (2003). A search model of marriage and divorce. Review of Economic Dynamics, 6(1), 135-155.

Crawford, D. W., Houts, R. M., Huston, T. L., \& George, L. J. (2002). Compatibility, leisure, and satisfaction in marital relationships. Journal of Marriage and Family, 64(2), 433-449.

Deci, E. L., \& Ryan, R. M. (1987). The support of autonomy and the control of behavior. Journal of Personality and Social Psychology, 53(6), 1024-1037.

Deci, E. L., \& Ryan, R. M. (2000). The what and why of goal pursuits: Human needs and the selfdetermination of behavior. Psychological Inquiry, 11(4), 227-268.

Dew, J. \& Wilcox, W. B. (2011). If momma ain't happy: Explaining declines in marital satisfaction among new mothers. Journal of Marriage and Family, 73(1), 1-12.

Diener, E., Emmons, R.A., Larsen, R.J., \& Griffin, S. (1985). The satisfaction with life scale. Journal of Personality Assessment, 49(1), 71-75. 
Gager, C. T., \& Sanchez, L. (2003). Two as one? Couples' perceptions of time spent together, marital quality, and the risk of divorce. Journal of Family Issues, 24(1), 21-50.

Gagne, M. \& Deci, E. (2005). Self-determination theory and work motivation. Journal of Organizational Behavior, 26(4), 331-362.

Gaine, G. S., \& La Guardia, J. G. (2009). The unique contributions of motivations to maintain a relationship and motivations toward relational activities to relationship well-being. Motivation and Emotion, 33(2), 184-202.

Gaudreau, P., Fecteau, M. C., Perreault, S. (2010). Individual self-determination and relationship satisfaction of athletes in dyadic sports: Examining the moderating role of dyadic selfdetermination. Journal of Applied Sport Psychology, 22(1), 34-50.

Goff, S. J., Fick, D. S., \& Oppliger, R. A. (1997). The moderating effect of spouse support on the relation between serious leisure and spouses' perceived leisure-family conflict. Journal of Leisure Research, 29(1), 47- 60.

Goodsell, T. L., \& Harris, B. D. (2011). Family life and marathon running: Constraint, cooperation, and gender in a leisure activity. Journal of Leisure Research, 43(1), 80-109.

Gorchoff, S. M., John, O. P., \& Helson, R. (2008). Contextualizing change in marital satisfaction during middle age: An 18-year longitudinal study. Psychological Science, 19(11), 11941200.

Gotlib, I. H., Lewinsohn, P. M., \& Seeley, J. R. (1998). Consequences of depression during adolescence: Marital status and marital functioning in early adulthood. Journal of Abnormal Psychology, 107(4), 686-690.

Greenwood, J., Guner, N., Kocharkov, G., Santos, C. (2012). Technology and the changing family: A unified model of marriage, divorce, educational attainment and married female labor- 
force participation. National Bureau of Economic Research (NBER). Working Paper No. 17735.

Herridge, K. L., Shaw, S. M., \& Mannell, R. C. (2003). An exploration of women's leisure within heterosexual romantic relationships. Journal of Leisure Research, 35(3), 274-291.

Holman, T. B., \& Epperson, A. (1984). Family and leisure: A review of the literature with research recommendations. Journal of Leisure Research, 16(4), 277-294.

Holman, T. B., \& Jacquart, M. (1988). Leisure-activity patterns and marital satisfaction: A further test. Journal of Marriage and the Family, 50(1), 69-77.

Johnson, H. A., Zabriskie, R. B., \& Hill, B. (2006). The contribution of couple leisure involvement, leisure time, and leisure satisfaction to marital satisfaction. Marriage and Family Review, 40(1), 69-91.

Kabeer, N. (2000). The power to choose: Bangladeshi women and labour market decisions in London and Dhaka. London and New York: Verso.

Kabeer, N. (2007). Marriage, motherhood and masculinity in the global economy: Reconfigurations of personal and economic life. Bringhton, UK: Institute of Development Studies.

Kleiber, D. A. (1999). Leisure experience and human development: A dialectical interpretation. New York, NY: Basic Books.

Kline, R. B. (2005). Principles and practice of structural equation modeling (2nd ed.). New York, NY: Guilford Press.

Knee, C. R., Patrick, H., Vietor, N. A., Nanayakkara, A., \& Neighbors, C. (2002). Selfdetermination as growth motivation in romantic relationships. Personality and Social Psychology Bulletin, 28(5), 609-619. 
La Guardia, J. G., \& Patrick, H. (2008). Self-determination theory as a fundamental theory of close relationships. Canadian Psychology, 49(3), 201-209.

La Guardia, J. G., Ryan, R. M., Couchman, C. E., \& Deci, E. L. (2000). Within-person variation in security of attachment: A self-determination theory perspective on attachment, need fulfillment, and well-being. Journal of Personality and Social Psychology, 79(3), 367-384.

Langer, A., Lawrence, E., \& Barry, R. A. (2008). Using a vulnerability-stress-adaptation framework to predict physical aggression trajectories in newlywed marriage. Journal of Consulting and Clinical Psychology, 76(5), 756-768.

Lavner, J. A., \& Bradbury, T. N. (2010). Patterns of change in marital satisfaction over the newlywed years. Journal of Marriage and Family, 72(5), 1171-1187.

Lundberg, N. R. (2009). The therapeutic use of community-based sports and recreation in the development of self-determined behavior: A case study. Annual in Therapeutic Recreation, $17,11-17$.

MacKinnon, D. P., Fairchild, A. J., \& Fritz, M. S. (2007). Mediation analysis. Annual Review of Psychology, 58, 593-614.

MacKinnon, D. P., Lockwood, C. M., Hoffman, J. M., West, S. G., \& Sheets, V. (2002). A comparison of methods to test mediation and other intervening variable effects. Psychological Methods, 7(1), 83-104.

Mead, D. E. (2002). Marital distress, co-occurring depression, and marital therapy: A review. Journal of Marital and Family Therapy, 28(3), 299-314.

Neff, L. A., \& Karney, B. R. (2007). Stress crossover in newlywed marriage: A longitudinal and dyadic perspective. Journal of Marriage and Family, 69(3), 594-607. 
Orthner, D. (1975). Leisure activity patterns and marital satisfaction over the marital career. Journal of Marriage and the Family, 37(1), 91-102.

Orthner, D. K., \& Mancini, J. A. (1991). Benefits of leisure for family bonding. In B. L. Driver, P. J. Brown, \& G. L. Peterson, (Eds.), Benefits of leisure (pp. 215-247). State College, PA: Venture Publishing.

Patrick, H., Knee, C. R., Canevello, A., \& Lonsbary, C. (2007). The role of need fulfillment in relationship functioning and well-being: A self-determination theory perspective. Journal of Personality and Social Psychology, 92(3), 434-457.

Rehman, U. S., Janssen, E., Newhouse, S., Heiman, J., Holtzworth-Munroe, A., Fallis, E., \& Rafaeli, E. (2011). Marital satisfaction and communication behaviors during sexual and nonsexual conflict discussions in newlywed couples: A pilot study. Journal of Sex \& Marital Therapy, 37(2), 94-103.

Reis, H. T., Sheldon, K. M., Gable, S. L., Roscoe, J., \& Ryan, R. M. (2000). Daily well-being: The role of autonomy, competence, and relatedness. Personality \& social psychology bulletin, 26(4), 419-435.

Ricard, N. C., Beaudry, S. G., \& Pelletier, L. G. (2012). Lovers with happy feet the interdependece of relationship and activity factors for individuals dancing with a romantic partner. Journal of Applied Social Psychology, 42(4), 939-963.

Rogers, S. J., \& Amato, P. R. (1997). Is marital quality declining? The evidence from two generations. Social Forces, 75(3), 1089-1100.

Ryan, R. M., \& Deci, E. L. (2000). Self-determination theory and the facilitation of intrinsic motivation, social development, and wellbeing. American Psychologist, 55(1), 68-78. 
Ryan, R. M., \& Deci, E. L. (2007). Active human nature: Self-Determination theory and the promotion and maintenance of sport, exercise, and health. In M. S. Hagger \& N. L. D. Chatzisarantis (Eds.), Intrinsic Motivation and Self-Determination in Exercise and Sport (pp. 1-19). Champaign, IL: Human Kinetics.

Saxbe, D. E., Repetti, R. L., \& Graesch, A. P. (2011). Time spent in housework and leisure: Links with parents' physiological recovery from work. Journal of Family Psychology, 25(2), 271281.

Saxbe, D. E., Repetti, R. L., \& Nishina, A. (2008). Marital satisfaction, recovery from work, and diurnal cortisol among men and women. Health Psychology, 27(1), 15-25.

Schneider, B., Ainbinder, A.M., \& Csikszentmihalyi, M. (2004). Stress and working parents. In J.T. Haworth \& A.J. Veal (Eds.), Work and Leisure (pp. 145-167). London: Routledge.

Shaw, S. M. (1985). The meaning of leisure in everyday life. Leisure Sciences, 7(1), 1-24.

Skowron, E. A. (2000). The role of differentiation of self in marital adjustment. Journal of Counseling Psychology, 47(2), 229-237.

Slatcher, R. B., Robles, T. F., Repetti, R. L., \& Fellows, M. D. (2010). Momentary work worries, marital disclosure, and salivary cortisol among parents of young children. Psychosomatic Medicine, 72(9), 887-896.

Sturge-Apple, M. L., Davies, P. T., \& Cummings E. M. (2006). Hostility and withdrawal in marital conflict: Effects on parental emotional unavailability and inconsistent discipline. Journal of Family Psychology, 20(2), 227-238.

Twenge, J. M., Campbell, W. K., \& Foster, C. A. (2003). Parenthood and marital satisfaction: A meta-analytic review. Journal of Marriage and Family, 66(3), 574-583. 
Ward, P. J., Barney, K., Lundberg, N., \& Zabriskie, R. B. (2013, accepted for publication). A Critical examination of couple leisure and the application of the core and balance model. Journal of Leisure Research.

Ward, P. J., Clark, T., Zabriskie, R., \& Morris, T. (2012). Paper/pencil versus online data collection: An exploratory study. Journal of Leisure Research, 44(4), 507-530.

Ward, P. J., Lundberg, N. R., Zabriskie, R. B., \& Berrett, K. (2009). Measuring marital satisfaction: A comparison of the revised dyadic adjustment scale and the satisfaction with married life scale. Marriage \& Family Review, 45(4), 412-429.

Weinstein, N., Hodgins, H. S., \& Ryan R. M. (2010). Autonomy and control in dyads Effects on interaction quality and joint creative performance. Personality and Social Psychology Bulletin, 36(12), 1603-1617.

Williamson, M., Zabriskie, R. B., Fellingham, G., Ward, P., \& Lundberg, N. (2013, under review). A National Examination of Couple Leisure and Marital Satisfaction: A Mixed Model Approach. Submitted to Leisure Science.

Zabriskie, R. B. (2000). An examination of family and leisure behavior among families with middle school aged children. Unpublished doctoral dissertation, Indiana University, Bloomington, Indiana.

Zabriskie, R. B., \& McCormick, B. P. (2001). The influences of family leisure patterns on perceptions of family functioning. Family Relations, 50(3), 281-289. 
Table 1

Descriptives for TCLS, FPNL, Autonomy, Competence, Relatedness, and MS

\begin{tabular}{|c|c|c|c|c|c|c|}
\hline Variables $^{\mathrm{a}}$ & $M$ & $S D$ & Skewness & Kurtosis & $L L$ & $U L$ \\
\hline TCLS & 23,565 & 4,526 & $-0,563$ & 0,371 & 6,000 & 30,000 \\
\hline FPNL & 52,500 & 10,208 & $-0,990$ & 0,403 & 9,000 & 63,000 \\
\hline Autonomy & 17,935 & 3,514 & $-1,181$ & 0,862 & 3,000 & 21,000 \\
\hline Competence & 17,555 & 3,613 & $-0,968$ & 0,296 & 3,000 & 21,000 \\
\hline Relatedness & 17,011 & 4,146 & $-1,008$ & 0,371 & 3,000 & 21,000 \\
\hline MS & 27,688 & 7,544 & $-1,242$ & 0,800 & 5,000 & 35,000 \\
\hline
\end{tabular}

${ }^{\mathrm{a}} \mathrm{N}=2374$. All displayed variables had no missing data. 
Table 2

Correlations between TCLS, FPNL, and MS

\begin{tabular}{|c|c|c|c|}
\hline & TCLS & FPNL & MS \\
\hline TCLS & 1 & $.551^{* *}$ & $.648^{* *}$ \\
\hline FPNL & $.551^{* *}$ & 1 & $.630^{* *}$ \\
\hline MS & $.648^{* *}$ & $.630^{* *}$ & 1 \\
\hline$* * \mathrm{p}<.01$ & & & \\
\hline
\end{tabular}


Table 3

Estimates for Path Analysis and Hybrid Models

\begin{tabular}{|c|c|c|c|c|c|c|c|c|c|}
\hline & \multicolumn{3}{|c|}{ Path Analysis } & \multicolumn{6}{|c|}{ Hybrid Models } \\
\hline & $\beta$ & $\begin{array}{c}\text { Std Ind } \\
\text { Effect }\end{array}$ & $\begin{array}{c}\text { Sobel } \\
\text { Test }\end{array}$ & $\beta$ & $\begin{array}{c}\text { Std Ind } \\
\text { Effect }\end{array}$ & $\begin{array}{c}\text { Sobel } \\
\text { Test }\end{array}$ & CFI & RMSEA & SRMR \\
\hline $\begin{array}{l}\text { Model } 1 \text { - } \\
\text { FPNL }\end{array}$ & & 0.216 & $18.228 *$ & & 0.437 & $22.775^{*}$ & 0.963 & 0.062 & 0.066 \\
\hline Path a & $0.551 *$ & & & $0.599 *$ & & & & & \\
\hline Path b & $0.392 *$ & & & $0.729 *$ & & & & & \\
\hline Path $c^{a}$ & $0.648^{*}$ & & & $0.717^{*}$ & & & & & \\
\hline Path c' & $0.432 *$ & & & $0.281 *$ & & & & & \\
\hline $\begin{array}{l}\text { Model } 2 \text { - } \\
\text { Autonomy }\end{array}$ & & 0.130 & $13.942 *$ & & 0.423 & $21.215^{*}$ & 0.987 & 0.045 & 0.030 \\
\hline Path a & $0.470 *$ & & & $0.573 *$ & & & & & \\
\hline Path b & $0.277^{*}$ & & & $0.738 *$ & & & & & \\
\hline Path c ${ }^{a}$ & $0.648^{*}$ & & & $0.717 *$ & & & & & \\
\hline Path c' & $0.518^{*}$ & & & $0.294 *$ & & & & & \\
\hline $\begin{array}{l}\text { Model } 3 \text { - } \\
\text { Competence }\end{array}$ & & 0.093 & $11.218 *$ & & 0.392 & $19.250 *$ & 0.989 & 0.041 & 0.028 \\
\hline Path a & $0.429 *$ & & & $0.530 *$ & & & & & \\
\hline Path b & $0.216^{*}$ & & & $0.740 *$ & & & & & \\
\hline Path c ${ }^{a}$ & $0.648 *$ & & & $0.717 *$ & & & & & \\
\hline Path c' & $0.555^{*}$ & & & $0.326^{*}$ & & & & & \\
\hline $\begin{array}{l}\text { Model } 4 \text { - } \\
\text { Relatedness } \\
\end{array}$ & & 0.297 & $23.790 *$ & & 0.578 & $25.084^{*}$ & 0.989 & 0.044 & 0.029 \\
\hline Path a & $0.584^{*}$ & & & $0.699 *$ & & & & & \\
\hline Path b & $0.509 *$ & & & $0.826^{*}$ & & & & & \\
\hline Path c ${ }^{a}$ & $0.648 *$ & & & $0.717^{*}$ & & & & & \\
\hline Path c' & $0.351 *$ & & & $0.140 *$ & & & & & \\
\hline $\begin{array}{l}\text { Model } 5 \text { - } \\
\text { Hybrid model }\end{array}$ & & & & & 0.303 & $16.685 *$ & 0.989 & 0.045 & 0.029 \\
\hline Path a & & & & $0.639 *$ & & & & & \\
\hline Path b & & $* *$ & & $0.474 *$ & & & & & \\
\hline Path c ${ }^{a}$ & & & & $0.717 *$ & & & & & \\
\hline Path c' & & & & $0.412 *$ & & & & & \\
\hline
\end{tabular}

\section{${ }^{\mathrm{a}}$ Path c represents the total effect}

$* \mathrm{p}<.001 ; * *$ Model 5 is originally a hybrid model 


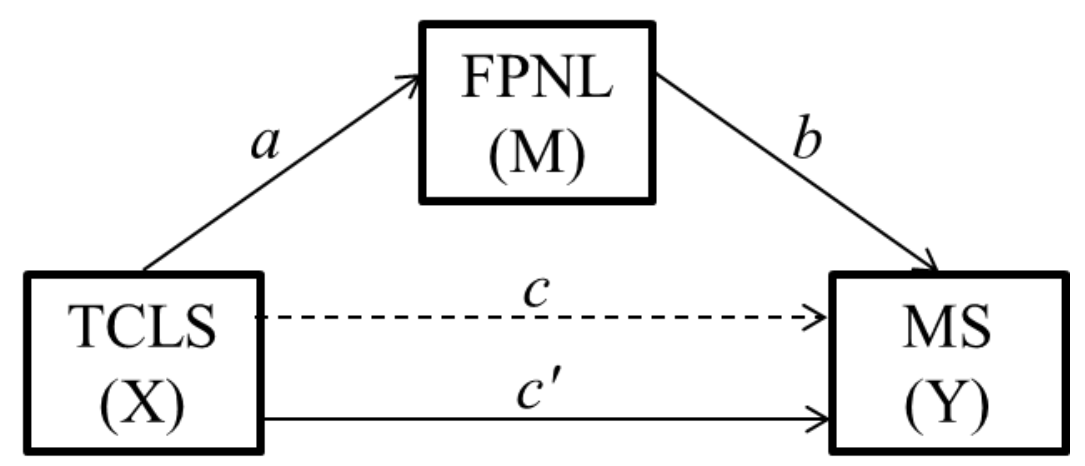

Figure 1. Model 1 - The mediating effects of FPNL. 

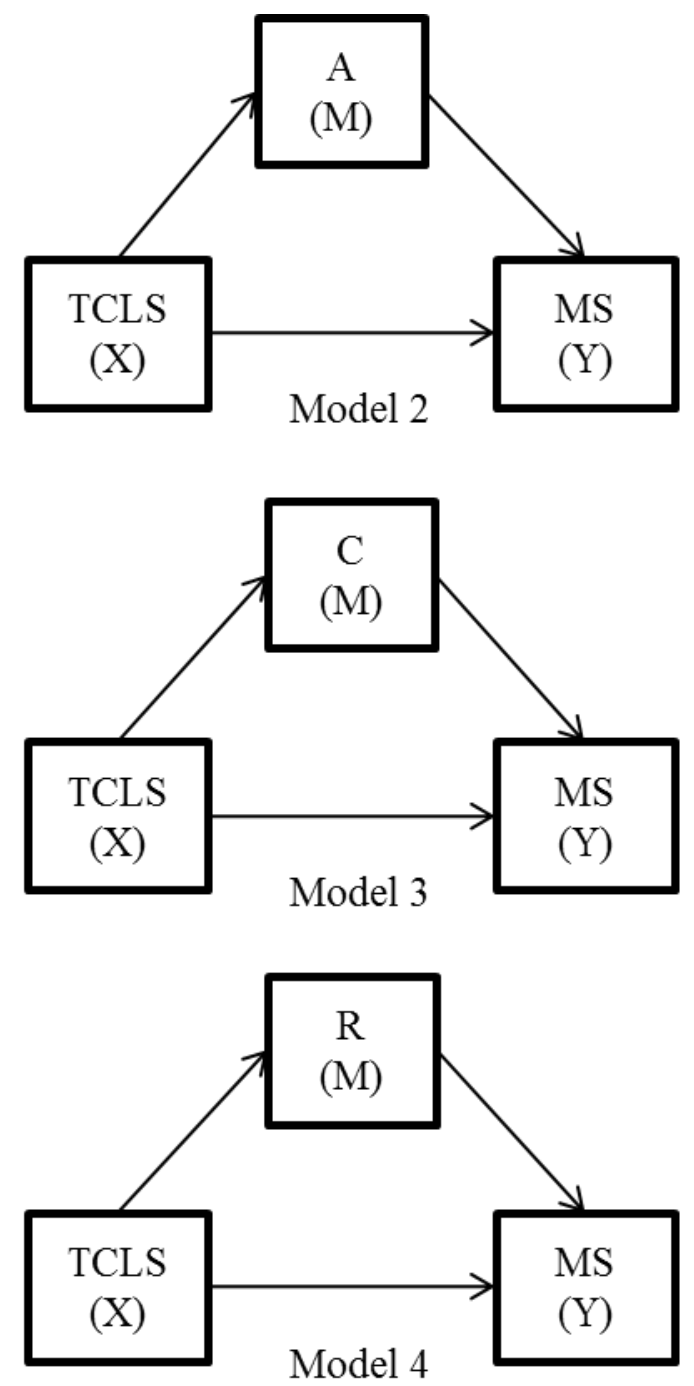

Figure 2. Models for the individual mediating effects of Autonomy (A), Competence (C), and Relatedness (R). 


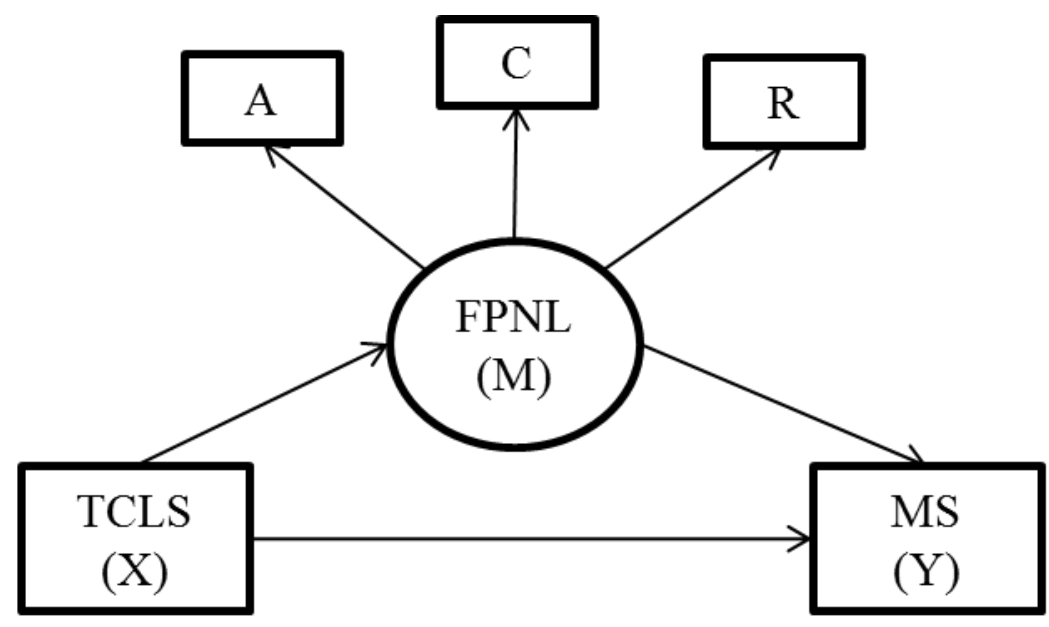

Figure 3. Model 5 - Autonomy (A), Competence (C), and Relatedness (R) influencing the mediating effect of FPNL. 

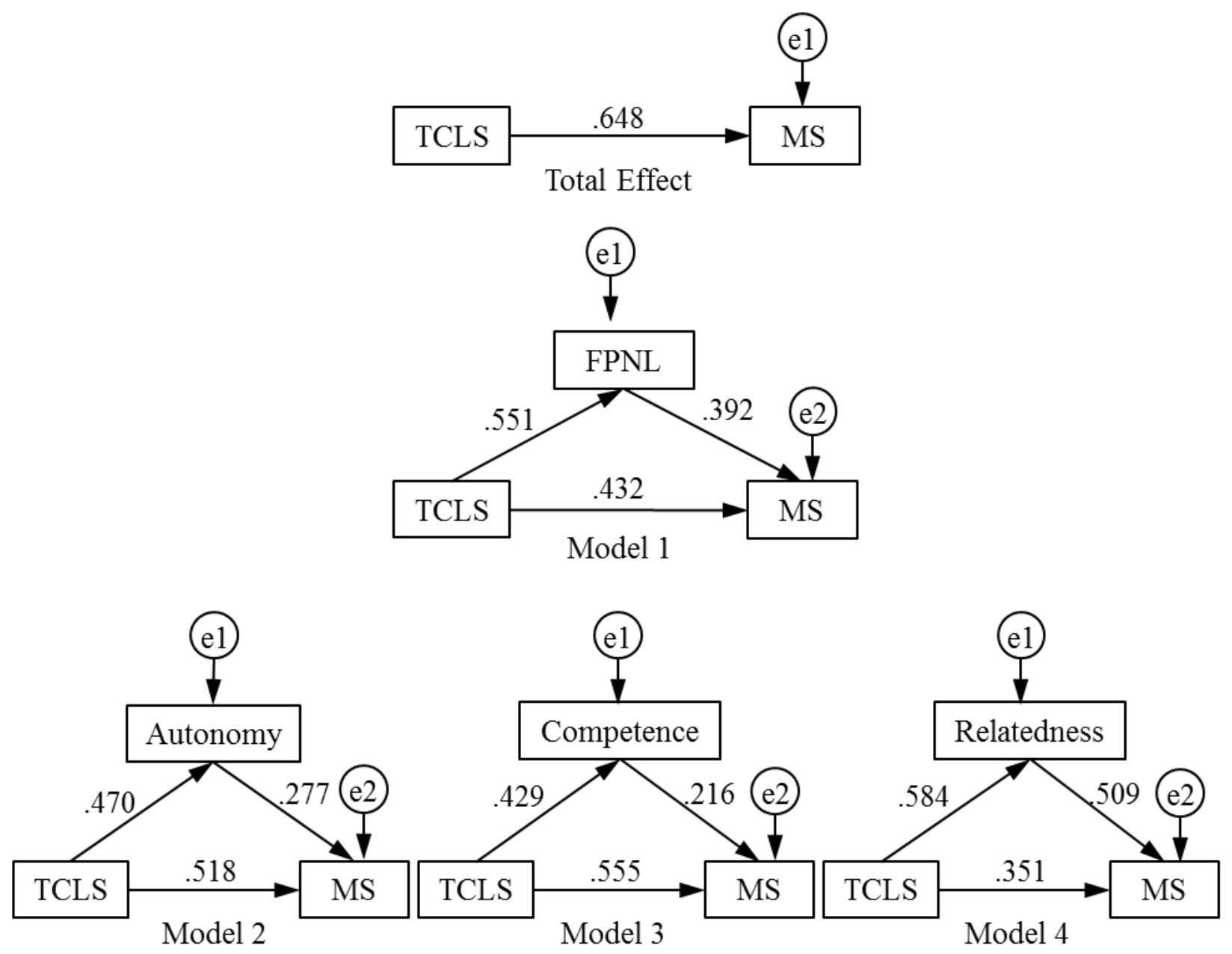

Figure 4. Total effect and path analysis for models 1 to 4 . 


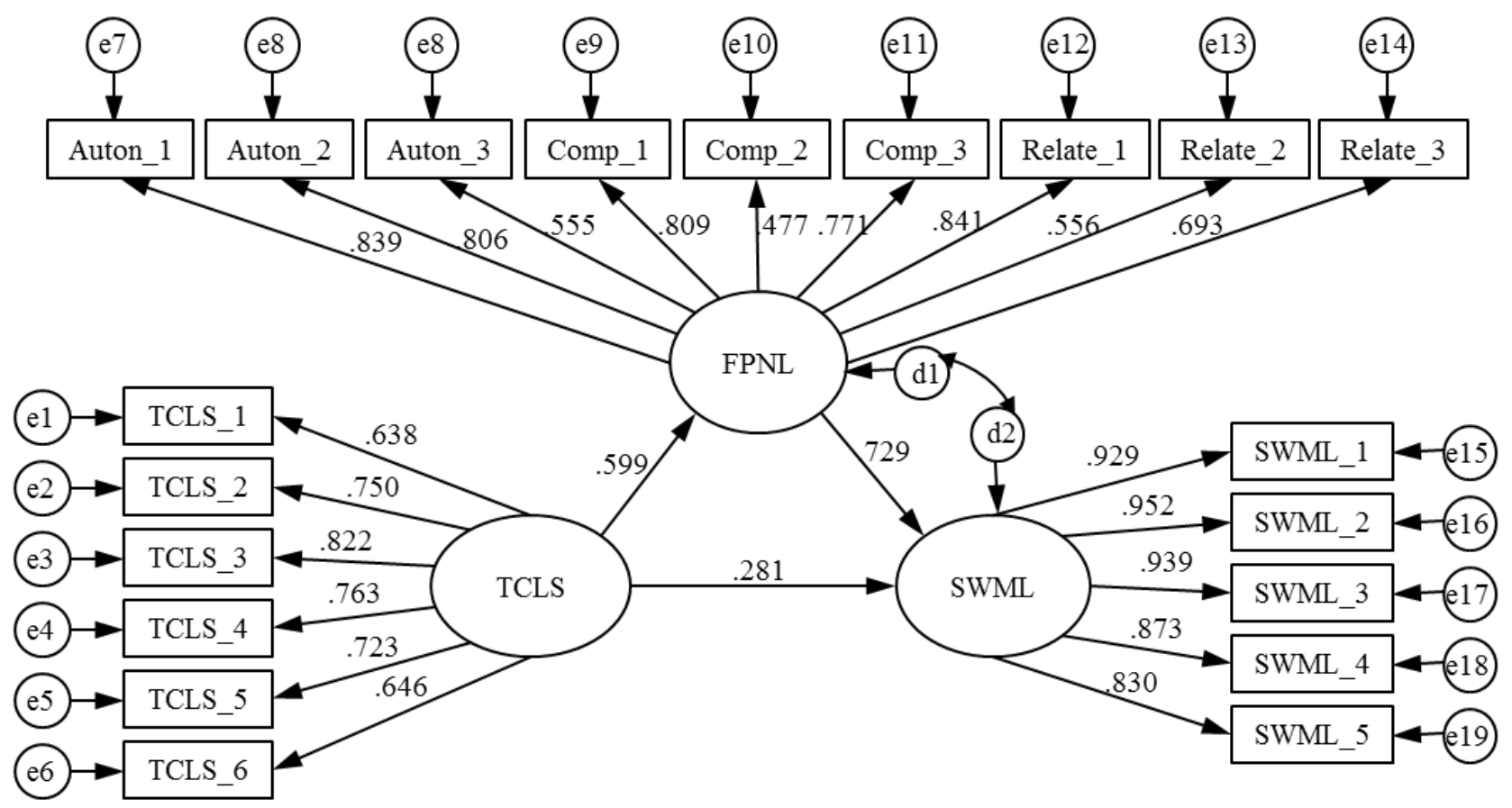

Figure 5. Hybrid model 1.

Note: Correlations between measurement errors were omitted in order to guarantee the clarity of the figure. 


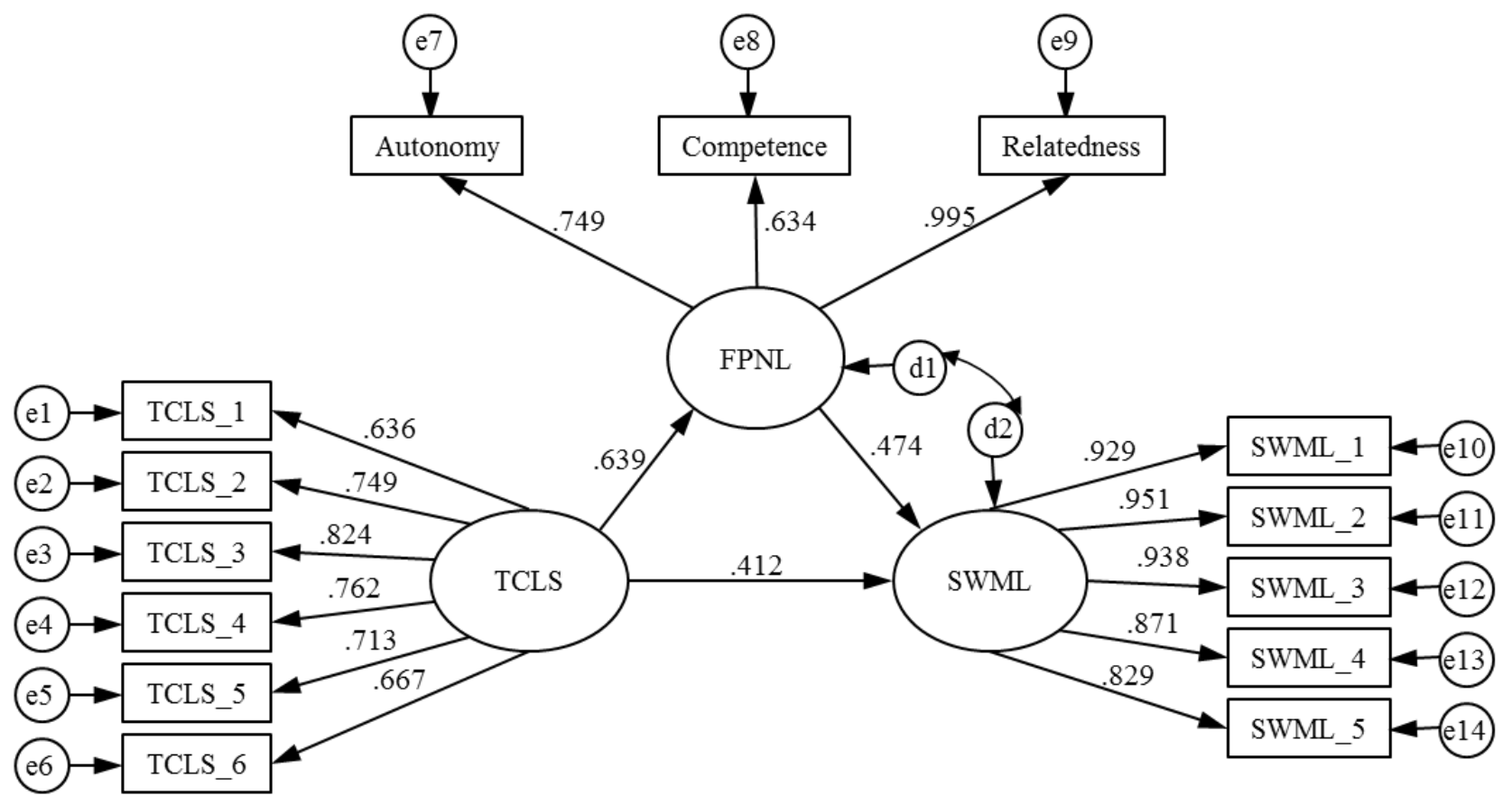

Figure 6. Hybrid model 5.

Note: Correlations between measurement errors were omitted in order to guarantee the clarity of the figure. 
Appendix A: Prospectus 


\section{Chapter 1}

\section{Introduction}

Economic and social changes over the past decades have negatively influenced marital relationships (Cornelius, 2003; Kabeer, 2000, 2007). Statisticians have pointed out that unemployment, women in the work-force, individualism, and the devaluation of marriage have significant associations with marital distress and divorce (Schaller, 2012; Teachman, Tedrow, \& Crowder, 2000). As a result, numerous studies have reported the negative outcomes of distressed marriages on adults' physical and emotional well-being, child development, and public safety (McCord, 1991; Saxbe, Repetti, \& Graesch, 2011; Schneider, Ainbinder, \& Csikszentmihalyi, 2004).

The rush of today's world is an additional factor that contributes to unsatisfactory marital relationships (Schneider, Ainbinder, \& Csikszentmihalyi, 2004). Walking in the park, sitting down to talk, and other simple activities that couples once frequently engaged in during their leisure time seem to be gradually losing their availability and importance (Appleton \& Bohm, 2001). The battle to provide financial support for the family, the struggle of raising children, and the use of technological and media devices have been challenging issues for husbands and wives (Ahlstrom, Lundberg, Zabriskie, Eggett, \& Lindsay, 2012; Claxton \& Perry-Jenkins, 2008; Greenwood, Guner, Kocharkov, Santos, 2012).

Given these modern challenges to marital stability, the need to strengthen marriages and families becomes clear and widely applicable. Dedicating effort to spending time together has been demonstrated as an essential tool to fortify marital ties and to diminish the negative effects that modern life potentially brings to marriages (Holman \& Epperson, 1984; Orthner \& Mancini, 1991). Scholars, however, have revealed that simply being together or being involved in leisure 
together is not enough to maintain a solid relationship. In order to strengthen their union, couples are to engage in activities in which both spouses are satisfied (Crawford, Houts, Huston, \& George, 2002; Johnson, Zabriskie, \& Hill, 2006). The present study, then, investigates reasons why being satisfied with couple leisure is associated with marital satisfaction.

\section{Problem Statement}

Literature on the association between couple leisure satisfaction and marital satisfaction is gradually evolving. Additional clarification, however, is still needed. For that reason, this study investigates the fulfillment of autonomy, competence, and relatedness as mediating variables to explain the existing relationship between total couple leisure satisfaction and marital satisfaction.

\section{Purpose of the study}

The purpose of this study is to investigate the mediating effects of autonomy, competence, and relatedness in explaining the relationship between couple leisure satisfaction and marital satisfaction. The results of this study aim to provide additional information to family science scholars and therapists so they may effectively guide couples toward treating marital distresses, strengthening marital relationships, and, consequently, preventing divorce and improving married life.

\section{Significance of the study}

Research investigating the welfare of marriage and family has gradually evolved over the past decades. Scholars focusing specifically on the importance of couple leisure for the maintenance and nourishment of marriages have also revealed significant findings. Four decades ago, Orthner (1975) compared the influence of three leisure patterns (individual, parallel, and joint activities) on marital satisfaction. He reported that joint activities, in which couples presented the highest levels of interaction and open communication, demonstrated the most positive impact on 
marriage quality. Recent studies (Ahlstrom, Lundberg, Zabriskie, Eggett, \& Lindsay, 2012; Berg, Trost, Schneider, \& Allison, 2001; Crawford, Houts, Huston, \& George, 2002; Johnson, Zabriskie, \& Hill, 2006), however, have further indicated that being satisfied with couple leisure contributes more to marital satisfaction than merely spending leisure time together. Although these studies added clarification on the relationship between couple leisure and marital satisfaction, they offered little theoretical foundation to explain this association, suggesting the need for additional investigation.

A similar line of research has explored the importance of spousal leisure support to strengthen marital relationships. Baldwin, Ellis, and Baldwin (1999) looked at the association between leisure support and marital satisfaction where at least one spouse runs frequently. Their results also contradicted Orthner's conclusion that individual leisure was negatively associated with marital satisfaction. Baldwin et al. suggested that the presence of support in leisure activities seemed to be more significant in determining satisfied marriages than the participation in joint activities. In addition to this conclusion, Goodsell and Harris's (2012) results supposed that combining leisure support and joint participation would provide even greater benefits toward marital satisfaction. Even though these studies contributed to the body of research on marital satisfaction by finding relationship with leisure support, they didn't specifically use a framework or theory to explain their results.

The present study combines and expands the efforts of both lines of research described above related to marital satisfaction (i.e., satisfaction with leisure and leisure support). We propose to contribute to the published literature by using the Self-Determination Theory as a mechanism to better understand the association between couple leisure satisfaction and marital satisfaction. In addition to this main objective, this study will also add to the body of literature by 
using a nationally reflective sample, whereas previous studies only gathered small samples (Berg et al., 2001; Crawford et al., 2002; Johnson et al., 2006).

\section{Assumptions}

1. Spouses will complete questionnaires separately in order to avoid biased responses.

2. The greater the fulfillment of psychological needs, the better the marital satisfaction.

3. The greater the marital satisfaction, the better the relationship between spouses.

\section{Research Hypotheses}

The study was designed to test the following hypotheses:

H1. Fulfillment of psychological needs during couple leisure is a significant mediator between total couple leisure satisfaction and marital satisfaction.

H2. Autonomy is a significant mediator between total couple leisure satisfaction and marital satisfaction.

H3. Competence is a significant mediator between total couple leisure satisfaction and marital satisfaction.

H4. Relatedness is a significant mediator between total couple leisure satisfaction and marital satisfaction.

H5. Autonomy, competence, and relatedness are significant mediators between total couple leisure satisfaction and marital satisfaction.

\section{Definition of terms}

The following terms are defined to clarify their use in the study:

1. Autonomy. “... involves acting with a sense of volition and having the experience of choice" (Gagne \& Deci, 2005, p. 333). 
2. Balance couple leisure. The type of leisure that is less common, less frequent, and mostly not home-based (i.e., vacations, camping, fishing, and attending a theatrical performance) (Zabriskie \& McCormick, 2001).

3. Competence. One's ability to perform tasks effectively.

4. Core couple leisure. The type of leisure occurring on a regular basis and mostly within or around the couple's residence (i.e., doing the following activities together: eating, watching television, and going on walks) (Zabriskie \& McCormick, 2001).

5. Couple. A relationship between two individuals that were considered domestic partners.

6. Intrinsic motivation. Active engagement in tasks solely for spontaneous enjoyment and personal satisfaction rather than having the expectation of specific outcomes (e.g., obtain rewards, avoid punishments).

7. Leisure. "The combination of free time and the expectation of preferred experience" (Kleiber, 1999, p. 3).

8. Marital satisfaction. "An individual's emotional state of being content with the interactions, experiences, and expectations of his or her married life" (Ward, Lundberg, Zabriskie, \& Berrett, 2009, p. 415).

9. Psychological needs. Self-determination theory (SDT) postulated that the satisfaction of autonomy, competence, and relatedness - the three innate psychological needsyields enhanced self-motivation and mental health while their suppression leads to diminished motivation and well-being (Ryan \& Deci, 2000).

10. Relatedness. "... feeling that one is close and connected to significant others" (Gable, Roscoe, \& Ryan, 2000, p. 420). 
11. Self-Determination Theory (SDT). An approach to "the investigation of people's inherent growth tendencies and innate psychological needs that are the basis for their self-motivation and personality integration" (Ryan \& Deci, 2000, p. 68).

\section{Delimitations}

The study was delimited to the following:

1. Data were collected from 1226 couples nation-wide, sampled via an online questionnaire.

2. Couples were recruited from the 48 continental states using a professional sampling service representing approximately $70 \%$ of the population that can be reached online.

3. The data for this study were collected during the months of February and March 2007.

4. Structural Equation Modeling will be the analytical procedure.

\section{Limitations}

The structure of this study will be limited by the following factors:

1. Ethnicity: Although the researchers intend to assess an equal amount of participants from the major ethnicities within the United States (European Americans, African Americans, Latin Americans), it is presumed that the majority of the participants will be white.

2. Generalizability: The sample analyzed in this study does not represent worldwide population in terms of race and type of union (marriage, cohabitation, remarried, etc.). Therefore, generalizability may be limited.

3. Modified Instrument: The questionnaire used to measure fulfillment of psychological needs in couple leisure was an adapted version of the original instrument developed by La Guardia, Ryan, Couchman, and Deci (2000). It is important, therefore, to 
recognize that the validity and reliability of this measure can be compromised with the additions to the original instrument.

4. Cross-sectional Design: Since literature has demonstrated the limitations of crosssectional studies in effectively measuring marital satisfaction (Gorchoff et al., 2008; Lavner \& Bradbury, 2010; Levenson, Carstensen, \& Gottman, 1993), the fact that the present study doesn't utilize a longitudinal method to collect data represents a limitation.

5. Correlational Study: A correlational strategy limits this study by not permitting the determination of causality between variables.

6. Unidentified Variables: There may be other variables playing an influential role in the prediction of marital satisfaction with which the present study was unaware of. 


\section{Chapter 2}

\section{Review of Literature}

The problem of this study is to investigate the fulfillment of autonomy, competence, and relatedness during couple leisure as mediating variables to explain the relationship between couple leisure satisfaction and marital satisfaction. In order to understand the variables being studied, the next paragraphs will delineate the importance of the self-determination theory (SDT), specifically the fulfillment of psychological needs (autonomy, competence, and relatedness), in explaining the relationship between couple leisure satisfaction and marital satisfaction. The numerous studies presented here will be organized under the following subtitles: a) Marital Satisfaction; b) Couple Leisure and Marital Satisfaction; and c) Self-Determination Theory.

\section{Marital Satisfaction}

The ever-growing need for strengthening the well-being of individuals and families has led scholars in marriage and family research to investigate marital satisfaction in depth (Bradbury, Fincham, \& Beach, 2000). The processes of forming and maintaining satisfied marital relationships, as well as preventing or alleviating divorce, have been additional reasons to study marital satisfaction (Bradbury et al., 2000; Gorchoff, John, \& Helson, 2008; Lavner \& Bradbury, 2010; Rogers \& Amato, 1997).

A clear definition of marital satisfaction was given by Ward et al. (2009). They declared that marital satisfaction is "an individual's emotional state of being content with the interactions, experiences, and expectations of his or her married life" (p. 415). Other definitions explained that simply identifying positive elements within said marital interactions, experiences, and expectations does not necessarily mean being content with the relationship (Bradbury et al., 2000). Similarly, perceiving negative elements may not be equal to unsatisfactory marriages. Marital satisfaction 
occurs when positive elements outweigh negative elements; likewise, marital dissatisfaction comes when negative elements overcome positive elements (Bradbury et al., 2000). Several studies have used the concept of marital satisfaction by following this or similar descriptions (Gorchoff et al., 2008; Lavner \& Bradbury, 2010; Levenson, Carstensen, \& Gottman, 1993).

Within the past decade, research has evidenced benefits of satisfied relationships for individuals. Studies have found that satisfying relationships diminish negative health effects related to stressful workloads (Saxbe, Repetti, \& Nishina, 2008), improve marital disclosure (Slatcher, Robles, Repetti, \& Fellows, 2010), and positively impact parental adaptation (Benson \& Kersh, 2011). Contrastingly, individuals in marriages marked by distress have a tendency to present less self-differentiation, higher levels of emotional cutoff and anxiety (Skowron, 2000), higher cortisol levels (which over the long term can have negative health effects, Saxbe et al., 2011), and greater susceptibility for parental emotional unavailability (Sturge-Apple, Davies, \& Cummings, 2006).

In addition to the above factors associated with marital satisfaction, researchers have identified at least five elements that have been associated with the quality of marital relationships (Bradbury et al., 2000; Lavner \& Bradbury, 2010). First, personal traits such as depression (Mead, 2002; Gotlib, Lewinsohn, \& Seeley, 1998) and aggressiveness (Langer, Lawrence, \& Barry, 2008) have been found to negatively impact marital quality. Second, life stressors such as financial problems (Bradbury et al., 2000) and work stress (Schneider et al., 2004) are also negatively associated with marital quality (Neff \& Karney, 2007). Third, the way couples communicate and discuss conflicts has been another predictor of marital satisfaction. A recent study comparing communication behaviors during nonsexual (e.g., financial, parenting) and sexual discussions suggested that "negativity expressed when discussing sexual topics may be a particularly potent 
predictor of marital satisfaction for newly married couples" (Rehman et al., 2011). The fourth element presented here is the presence of children at home. Twenge, Campbell, and Foster (2003) demonstrated that even though the responsibilities attached to child caregiving may diminish marital satisfaction, couples can still strengthen their relationship while parenting by properly distributing parental duties and communicating in a positive manner (Claxton \& Perry-Jenkins, 2008).

Finally, scholars have highlighted the importance of spousal time for marital satisfaction (Appleton \& Bohm, 2001; Dew \& Wilcox, 2011; Gager \& Sanchez, 2003). Appleton and Bohm investigated tactics mid-life couples used to strengthen their marriages and indicated that simple actions such as stopping to smell the roses or "just sitting" together contributed to the quality of couples' relationships. Activities that include "the combination of free time and the expectation of preferred experience" as well as a "lack of obligation" and a "sense of opportunity" are commonly considered leisure experiences (Kleiber, 1999, p. 3). When these activities are participated in with a significant other, they are frequently referred to as "couple leisure" (Johnson et al., 2006). The present study seeks to further understand the relationship between couple leisure activities and marital satisfaction.

\section{Couple Leisure and Marital Satisfaction}

Research on the association between couple leisure and marital satisfaction has gained importance over past decades. Orthner (1975) analyzed the influence of three leisure activity patterns on marital satisfaction. The activities included the following: individual (with no communication or interaction between spouses), parallel (with minimal couple interaction or communication), and joint (high interaction and open communication). His findings indicated that compared to individual and parallel activities, joint activities tended to present the most positive 
relationship toward marriage quality. Other studies also indicated that spouses who engaged in leisure activities together presented higher levels of marital satisfaction (Claxton \& Perry-Jenkins, 2008; Holman \& Epperson, 1984; Orthner \& Mancini, 1991). Particularly, research has demonstrated that couple leisure increases marital bonding and marital intimacy (Herridge, Shaw, \& Mannell, 2003), enhances couple communication (Holman \& Jacquart, 1988; Orthner, 1975), and decreases spouses' stress levels (Schneider et al., 2004).

In the past decade, studies have directly suggested that it is the satisfaction with couple leisure rather than simply the amount of time spent together in leisure that significantly contributed to relationship satisfaction (Berg et al., 2001; Crawford et al., 2002; Johnson et al., 2006). In fact, the longitudinal study conducted by Crawford et al. indicated that engagement in joint activities enjoyed only by husbands served as a detriment for wives satisfaction with marriage. Ahlstrom et al. (2012) provided additional evidence by studying couples that either one or both spouses played online games. They revealed that couples suffered marital distress when only one spouse engaged in this leisure activity. Spouses also suffered marital dissatisfaction when they participated together in online games but only one of them was satisfied with the activity. In contrast, higher levels of marital satisfaction were perceived when both spouses played online games and both were satisfied with the activity.

Apart from the significance of the findings presented above, little theoretical work has been done in order to explain the association between satisfaction with couple leisure and marital satisfaction. Johnson et al. (2006) utilized the Core and Balance framework to specifically examine the contribution of the type of couple leisure activities, amount of time spent on them, and satisfaction with couple leisure to overall marital satisfaction. Core couple leisure activities included the type of leisure that occurred on a regular basis and mostly within or around the 
couple's residence. Examples of core couple leisure include eating together, doing the dishes together, watching television together, and going on walks together. Balance couple leisure activities referred to the type of leisure that is less common, less frequent, and mostly not home based, such as vacations, camping, fishing, and attending a theatrical performance (Zabriskie \& McCormick, 2001). Johnson et al. revealed that compared to satisfaction with balance couple activities and the amount of involvement in joint activities, satisfaction with core couple leisure contributed the most to the explanation of increased levels of marital satisfaction. Despite these significant findings, Johnson et al. recognized that their study sample size of 48 couples was not reflective enough; therefore, they recommended reproducing their findings with a larger and more geographically diverse sample.

In response to aforementioned recommendation, two studies analyzed the relationship between couple leisure satisfaction and marital satisfaction using a sample of 1,187 couples across the United States (Williamson, Zabriskie, Fellingham, Ward, \& Lundberg, 2013; Ward, Barney, Lundberg, and Zabriskie, 2013). Both studies reaffirmed Johnson et al. indication that, in the context of leisure, core couple leisure satisfaction was the strongest single predictor of marital satisfaction. Ward et al. revealed, however, that core couple leisure satisfaction and balance couple leisure satisfaction were strongly correlated $(r=.886)$. Because the latent variables' correlation was stronger than .80 (Kline, 2005, 2011), these two variables were combined into a new variable, total couple leisure satisfaction, suggesting that although balance couple leisure satisfaction was a weaker contributor to overall marital satisfaction, the inclusion of balance activities would still increase levels of marital satisfaction, indicating the need of both core and balance leisure satisfaction in order to reach higher levels of marital satisfaction (Zabriskie \& 
McCormick, 2001). Ward et al. enhanced previous research by specifically identifying total couple leisure satisfaction as a strong and significant predictor of marital satisfaction.

Although these studies (Johnson et al., 2006; Ward et al., 2013; Williamson et al., 2013) offered additional understanding regarding the relationship between couple leisure and marital satisfaction, particularly identifying the important role of total couple leisure satisfaction, further theoretical examination is needed to understand why the element of satisfaction within couple leisure is so highly associated with marital satisfaction. The present study employs selfdetermination theory (SDT) as a mechanism, or explanatory framework, to further understand the association between total couple leisure satisfaction and marital satisfaction.

\section{Self-Determination Theory}

The fundamental idea of the SDT consists of the principles associated with the motivational levels of individuals (Ryan \& Deci, 2000). Deci and Ryan (2000) explained that motivational levels can vary from amotivation and extrinsic motivation to intrinsic motivation. Intrinsically motivated behaviors concern active engagement in tasks solely for spontaneous enjoyment and personal satisfaction. In contrast, extrinsically motivated behaviors have the expectation of specific outcomes, such as obtaining rewards and avoiding punishments. SDT claims that the achievement of intrinsic motivation occurs through the fulfillment of three basic psychological needs: autonomy, competence, and relatedness (Ryan \& Deci, 2007; Lundberg, 2009). It is important to distinguish each psychological need as they individually play a specific role in the development of intrinsic motivation. As stated by Gagne and Deci (2005), "autonomy involves acting with a sense of volition and having the experience of choice" (p. 333). In a simple description, autonomy is the opportunity to be in control of or the source of one's behavior. The competence need refers to an individual's ability to perform tasks effectively. Competence leads 
people to seek challenges that match their abilities and to either maintain or enhance those skills through involvement in activity. According to Reis, Sheldon, Gable, Roscoe, and Ryan (2000), "the need for relatedness pertains to feeling that one is close and connected to significant others" (p. 420). Fulfillment of these three psychological needs is associated not only to intrinsic motivation but also to personal growth, integrity, well-being (Deci \& Ryan, 2000), and marital satisfaction (La Guardia, Ryan, Couchman, \& Deci, 2000; La Guardia \& Patrick, 2008; Patrick, Knee, Canevello, \& Lonsbary, 2007).

\section{The relationship between fulfillment of psychological needs and marital satisfaction.}

Many studies linking SDT and marital satisfaction focused mostly on individuals' motivational levels in their marital relationships or on the implications of autonomy orientation versus control orientation within close relationships (Blais, Sabourin, Boucher, Vallerand, 1990; Gaine, \& La Guardia, 2009; Gaudreau, Fecteau, Perreault, 2010; Knee, Patrick, Vietor, Nanayakkara \& Neighbors, 2002; Weinstein, Hodgins, \& Ryan, 2010). These studies, however, left unmentioned the important role of fulfilling the three psychological needs. Few researchers have indicated that fulfillment of autonomy, competence, and relatedness within close relationships has important implications for relationship satisfaction (La Guardia et al., 2000; La Guardia \& Patrick, 2008). Patrick et al. (2007), in conducting three separate studies on the association between fulfillment of the three psychological needs and well-being among couples, found that the more one perceived needs being fulfilled by his or her partner, the greater was the relationship satisfaction and wellbeing, while their perceived conflict and defensive responses to conflict decreased. La Guardia and Patrick explained that in a close relationship, a needs- supportive individual engages in efforts to understand his or her partner's interests, preferences, and perspectives (autonomy); considers the partner's capacities and limitations (competence); and demonstrates continual care and diligent 
involvement toward the partner (relatedness). Despite these significant findings (Patrick et al. 2007, La Guardia \& Patrick, 2008), additional clarification is necessary in applying the fulfillment of psychological needs within specific areas of marriage (e.g., professional aspirations and raising children) and its impacts on marital satisfaction. The present study then proposes to specifically consider fulfillment of psychological needs during couple leisure and investigate its influence on marital satisfaction.

\section{Using fulfillment of psychological needs to understand the link between total couple}

leisure satisfaction and marital satisfaction. Family science literature has documented significant associations between fulfillment of psychological needs during couple leisure and relationship satisfaction (Baldwin et al., 1999; Goff, Fick, \& Oppliger, 1997; Goodsell \& Harris, 2011; Ricard, Beaudry, \& Pelletier, 2012). These studies, however, focused mostly on the fulfillment of the psychological need of autonomy, which is frequently mentioned as "autonomy support" or simply "support" (Deci \& Ryan, 1987). One example is Baldwin et al.'s investigation of the relationship between leisure support and marital satisfaction among married couples where at least one spouse runs frequently. Their results contradicted Orthner's (1975) conclusion that individual leisure was negatively associated with marital satisfaction. Baldwin et al. reported that when spouses supported partner's individual leisure (running), marital satisfaction was higher than when there was no support for individual leisure, and it was comparable to engagement in meaningful joint recreation. Although the study didn't specifically involve each of the three psychological needs, Baldwin et al. drew an important conclusion regarding leisure support. They suggested that the presence of support in leisure activities seemed to be more significant in determining satisfied marriages than the participation in shared or joint activities. 
Recent studies on spouses' motivational support in leisure activities revealed similar implications toward relationship satisfaction (Goff et al., 1997; Goodsell \& Harris, 2011; Ricard et al., 2012). Further regarding the influence of serious running on the quality of marital relationships, Goodsell and Harris identified that "although many non-runners were supportive of their spouses' running, this effect was amplified when both spouses shared an interest in running". Since people tend to choose to participate in activities they feel most interested in and satisfied with (Kleiber, 1999; Shaw, 1985), Goodsell and Harris's findings suggested that runners felt more supported by their spouses when they ran together and felt mutually satisfied with the activity. Their study also revealed that the benefits experienced by supportive spouses (both runners and non-runners) of runners included health and wellness, stress relief, meaningful ties, and stronger relationships. Otherwise stated, these findings suggested that combining support in leisure and joint participation would result in higher levels of marital satisfaction. While Goodsell and Harris's study contributed to the marital satisfaction body of research by finding associations with leisure support, it was not generalizable across populations because of its qualitative nature. In addition, the idea of leisure support Goodsell and Harris used in their study referred only to the psychological need of autonomy, as it occurred in Baldwin et al.'s study. Both studies left unexplored the importance of satisfying the three psychological needs in couple leisure to predict satisfied marriages. On the contrary, the influence of autonomy, competence, and relatedness have been separately analyzed in association to relationship functioning and well-being (La Guardia \& Patrick, 2008; Patrick et al., 2007). Patrick et al. reveled that "the fulfillment of each need individually predicted both individual and relationship well-being, with relatedness being the strongest unique predictor of relationship outcomes" (p. 434). They supposed that, although autonomy and competence have been traditionally reported as the most influential psychological 
need in achieving intrinsic motivation, relatedness plays a particularly important role in the context of close relationships. Therefore, the present study proposes to analyze the significance of fulfilling each psychological need as mediators between couple leisure satisfaction and marital satisfaction.

As previously stated, scholars have documented the positive association between couple leisure satisfaction and relationship satisfaction (Berg et al., 2001; Crawford et al., 2002; Johnson et al., 2006). Ward et al. (Under Review) especially demonstrated that total couple leisure satisfaction is a strong positive indicator of marital satisfaction. The present study, then, proposes to add to the reviewed literature by expanding the idea of need support in leisure (Goodsell \& Harris, 2011; Patrick et al, 2007) using the fulfillment of psychological needs (autonomy, competence, and relatedness) during couple leisure as mediators between total couple leisure satisfaction and marital satisfaction. 


\section{Chapter 3}

\section{Methods}

The problem of this study is to examine the mediating effects of autonomy, competence, and relatedness during couple leisure on the relationship between total couple leisure satisfaction and marital satisfaction. The following paragraphs will demonstrate the methodology of the study by explaining: (a) data collection procedures, (b) sample, (c) instrumentation, and (d) data analysis.

\section{Data Collection Procedures}

The present study is an analysis of data collected during 2007 (Ward, Lundberg, Zabriskie, \& Berrett, 2009; Ward, Barney, Lundberg, \& Zabriskie, 2013; Williamson, Zabriskie, Fellingham, Ward, \& Lundberg, 2013). Data was collected via Survey Sampling International using its data base of over two million US households. Online data collection and paper and pencil surveys have yielded similar results, demonstrating that there is not a significant difference between these two data collection procedures (Ward, Clark, Zabriskie, \& Morris, 2012). An e-mail with a link to the online questionnaire in Qualtrics was distributed to Survey Samplings International's data base until it reached the targeted sample of 1,200 couples. Couples were asked to independently answer the questionnaire in order to encourage authentic responses. After successfully completing the entire questionnaire, participant couples were compensated with a stipend paid by Survey Sampling International.

\section{Sample}

From the initial 1,226 couples, 39 were excluded due to unfinished questionnaires or extreme outliers in couple behavior (for example, reporting 20 hours of family dinner every day of the week). In addition, partners' responses of each of the 1,187 couples were compared to ensure 
compatibility of answers. Couples that demonstrated very different answers on the joint participation items were eliminated from the analysis.

Respondents of the current sample were residents of the four US regions: Northeast (23.8\%), Midwest (24.6\%), South (34.5\%), and West (17.2\%). The mean age for men was 52.0 $(\mathrm{SD}=13.80)$ and the mean age for women was $39.5(\mathrm{SD}=13.25)$. The mean annual household income ranged from less than $\$ 10,000$ to over $\$ 150,000$, with a mean and mode category of $\$ 40,000$ to $\$ 49,999$. Eighty-nine percent of the sample reported being currently married, and $57 \%$ percent reported being previously divorced. The ethnic majority of respondents were white $(2,242$ or $91.8 \%$ ) with minority represented by Black ( 88 or $3.6 \%$ ), Hispanic (52 or $2.1 \%$ ), Asian (26 or 1.1\%), Native American (27 or 1.1\%), and Pacific Islander (6 or .25\%). Forty-seven of the couples reported being in a same sex relationship, and of these relationships, 32 of the relationships were female. Overall, the current sample was generally reflective of the U.S. population census information.

\section{Instrumentation}

Data were collected using the following instruments: (a) a 15-item Marital Activity Profile (MAP) that measures involvement and satisfaction in core and balance couple leisure activities (Johnson et al., 2006) based on the Core and Balance Model of Family Leisure Functioning (Zabriskie, 2000); (b) a nine-item Fulfillment of Psychological Needs during Couple Leisure (FPNL) scale that measures the fulfillment of competence, autonomy and relatedness during couple leisure. The FPNL is a revised version of Need Satisfaction with Spouse Scale (NSSS) (LaGuardia et al., 2000); and (c) a five item Satisfaction with Married Life scale (SWML, Ward et al., 2009); and (d) relevant sociodemographic data. 
Marital Activity Profile (MAP). In order to measure the independent variable, total couple leisure satisfaction (TCLS), a 15-item MAP scale was used (see Appendix A Instrumentation). The MAP measures involvement and satisfaction in couple leisure activities and it is a modified version of the FLAP (Family Leisure Activity Profile, Zabriskie, 2000). The FLAP was based on the Core and Balance Model of Family Leisure Functioning (Zabriskie, 2000) and has demonstrated acceptable psychometric properties. FLAP's original words "with your family" was changed to "with your spouse" on the MAP in order to focus on marital relationships. In addition, other minor modifications were made to the MAP from the FLAP. These modifications were made in an effort to better fit the type of leisure activities in which couples may participate while maintaining the core and balance framework (e.g., household cooking/cleaning and leisurebased communication). All other aspects of the MAP, including format, scoring procedures, and leisure satisfaction items, remained the same as the FLAP.

The MAP contains questions on both core (e.g., home-based TV/video-watching together, regular communication, and playing games together) and balance (e.g., community based events, outdoor activities, adventure activities, and travel together) couple leisure. Eight questions represent core couple leisure activities and seven questions focus on balance couple leisure activities. Examples of core couple leisure and balance couple leisure questions include: "Do you have dinners, at home, with your spouse?" and "Do you participate in community-based special events (for example visiting museums, zoos, theme parks, fairs, etc.) with your spouse?" Respondents were asked whether or not they participated in different activities with their spouse. If participants responded "yes," they were asked to estimate the frequency ("About how often") and the duration of the activity ("For about how long each time"), as well as how satisfied (5-point 
Likert scale) they were with the couple activity. If respondents did not participate in the activity, they were still asked to rate their non-participation satisfaction.

Scores for the MAP were calculated by first multiplying the frequency and duration of participation in each category, and then summing the core categories to provide a core marital leisure involvement score and summing the balance categories to provide a balance marital leisure involvement score. The total couple leisure involvement score was calculated by summing the core and balance scores. The TCLS score was calculated by summing the satisfaction responses for the core items and balance items. The MAP has demonstrated acceptable psychometric properties including evidence of construct and content validity (Johnson et al., 2006).

Fulfillment of Psychological Needs during Couple Leisure (FPNL). The mediating variables, autonomy, competence, and relatedness, were measured through FPNL scale, a modified version of the nine-item Need Satisfaction with Spouse Scale (NSSS) (LaGuardia et al., 2000). While NSSS measures the fulfillment of each of the three basic psychological needs during interaction with spouse, FPNL focuses specifically on couple recreation. Thus, the original words "When I am with my spouse" in NSSS were substitute with "During our recreation participation" on FPNL.

Each of the three psychological needs contained three items on the questionnaire. Examples of autonomy, competence, and relatedness items are respectively "During our recreation participation, I feel like a competent person," "During our recreation participation, I feel free to be who I am," and "During our recreation participation, I often feel loved and cared about." Participants rated on a 7-point Likert scale $(1=$ not very true at all, $7=$ very true $)$ how well their psychological needs were met during couple leisure. Each psychological need score varied from 3 
to 21, and the total score (FPNL) was obtained through the sum of all items ranging from 9 to 63 . La Guardia et al., (2000) reported a Cronbach's Alpha of .88 for NSSS.

Satisfaction with Married Life (SWML). The dependent variable, marital satisfaction (MS), was measured using the five-item scale SWML (Ward et al., 2009). The SWML is a modified version of the Satisfaction with Life Scale (Diener, Emmons, Larsen, \& Griffin, 1985), where the word "life" was replaced by "married life." A sample item is "I am satisfied with my married life". Participants rated on a 7-point Likert-type scale $(1=$ strongly disagree, $7=$ strongly agree) each of the five items. The items were then summed producing a satisfaction with married life score ranging from 5 to 35 . The higher the score, the greater the satisfaction with married life. Previous Cronbach's alpha of .92 and .96 were respectively reported by Johnson et al. (2006) and Ward et al.

Demographics. The following categories were included in the demographic questioner in order to examine essential characteristics of the sample: (a) gender, (b) age, (c) ethnicity, (d) previous marital history, and (e) income (see Appendix A). Each of these will be used a controlling factor and to describe the sample.

\section{Data Analysis}

Structural equation modeling will be used in order to explore the mediating effects of FPNL on the relationship between TCLS and MS. MacKinnon, Fairchild, and Fritz (2007) described mediation as "the addition of a third variable to [the] $\mathrm{X} \rightarrow \mathrm{Y}$ relation, whereby $\mathrm{X}$ causes the mediator, $\mathrm{M}$, and $\mathrm{M}$ causes $\mathrm{Y}$, so $\mathrm{X} \rightarrow \mathrm{M} \rightarrow \mathrm{Y}$ ” (p. 595). Otherwise stated, mediation is the inclusion of a third variable that, when included in a regression model together with the independent variable (IV) and dependent variable (DV) significantly reduces the correlation between IV and DV (Baron \& Kenny, 1986). An additional explanation for mediation is that a 
direct effect is found when $\mathrm{X}$ is significantly correlated with $\mathrm{Y}$ while an indirect effect (also called mediated effect) occurs when the relationship between $\mathrm{X}$ and $\mathrm{Y}$ is significantly reduced by the inclusion of a mediating factor (MacKinnon et al.; MacKinnon, Lockwood, Hoffman, West, \& Sheets, 2002). Therefore, this study will explore TCLS (X) and its relationship to MS (Y) as mediated by FPNL (M) (see Figure 1) and test the indirect effect of FPNL using the Sobel test, as indicated in Baron and Kenny. The purpose of the Sobel test is to determine if the relationship between the IV and DV has been significantly reduced after including the mediator variable (MacKinnon et al., 2002).

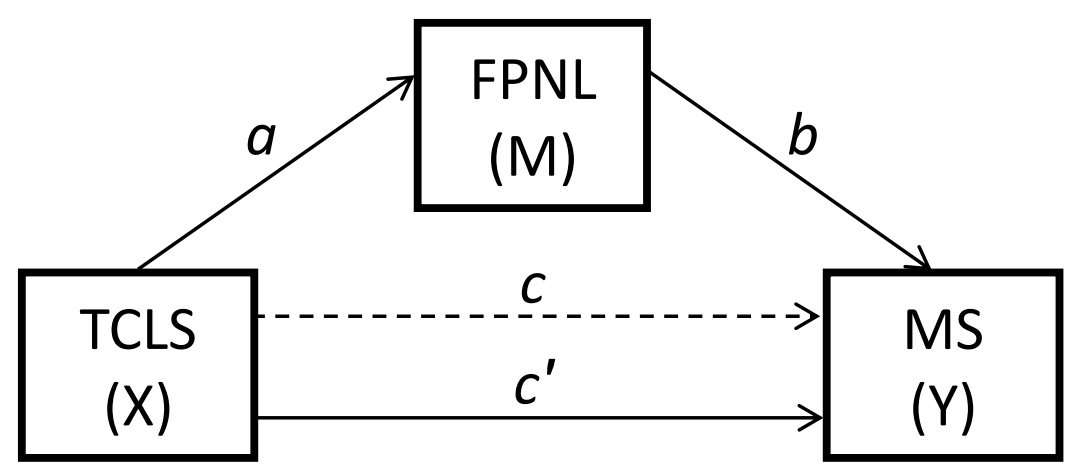

Figure 1. Model 1 - The mediating effects of FPNL.

The present study will implement Barron and Kenny's four-step approach to mediation (Baron \& Kenny, 1986; Bedini, Gladwell, Dudley, \& Clancy, 2011). First, there must be a significant relationship between TCLS to MS, path $\mathrm{c}$. Second, there must be a significant relationship between TCLS and FPNL, path a. Third, FPNL must be significantly related to MS when TCLS is also predicting MS, path b. Fourth, the relationship between TCLS and MS (path c') must be smaller after the inclusion of FPNL. If c' is zero, then the relationship between TCLS and MS has total mediation through FPNL. If $\mathrm{c}^{\prime}$ is greater than zero, but less than $\mathrm{c}$ the relationship between TCLS to MS is partially mediated by FPNL. 
The model presented above (Figure 1), however, is but the first step of the analysis. It covers only a general perspective of the mediating effect of psychological needs. In order to investigate the influence of each psychological need separately, four additional models will be analyzed. Three models will examine each psychological need individually as a mediator on the relationship between TCLS and MS (Figure 2). This step will provide specific information on the significance and strength of the mediating effect of autonomy, competence, and relatedness. The third and last step of the analysis will be the investigation of the hybrid model (the facture structure of SDT and the SEM of the meditation between TCLS and SWML) in order to understand how the three psychological needs function together as mediators between TCLS and MS (Figure 3).
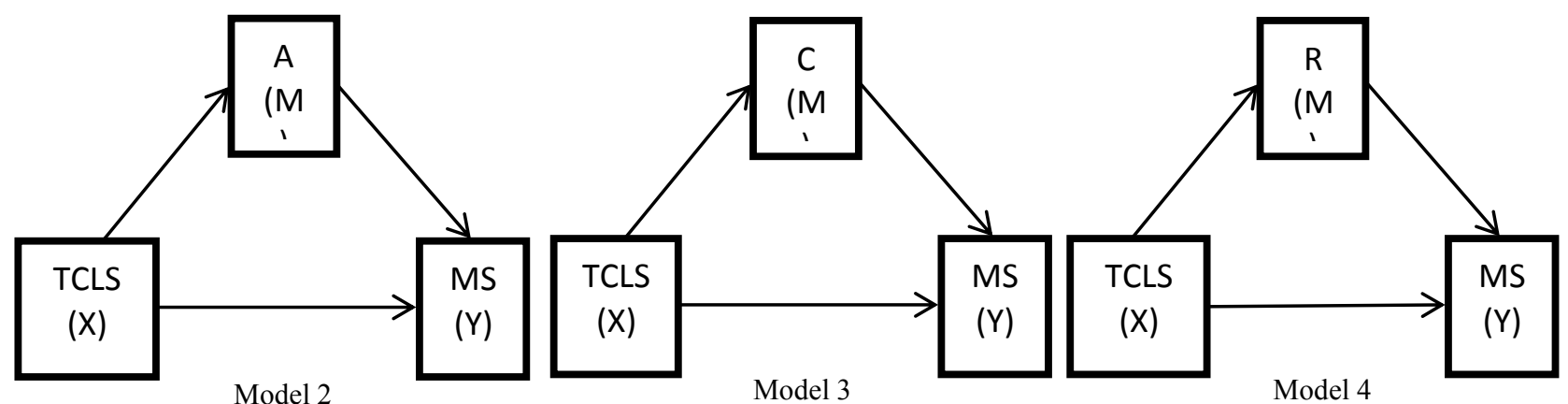

Figure 2. The individual mediating effects of autonomy (A), competence (C), and relatedness $(\mathrm{R})$.

In order to test the comparability between the hypothetical model and the collected data, several conservative model fit indices will be examined. First, a chi-square test. A nonsignificant chi-square statistic is unlikely (Kline, 2005) and a significant chi-square test is typically not used

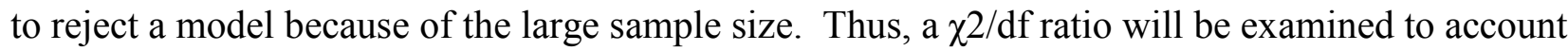
for the expected large sample size. This ratio is desired to be less than three. Second, the comparative fit index (CFI) will consider the model's absolute or parsimonious fit relative to the null or hypothetical model. An index score of .95 or greater is desired. Third, the root mean 
square error of the approximation (RMSEA) will be considered to assess fit based on the magnitude of the residuals. An index score of .08 or less is desired. Fourth, the standardized root mean square residual (SRMR) will be used to measure the standardized differences between the observed covariance and the predicted covariance. A value of less than .08 is considered a good fit.

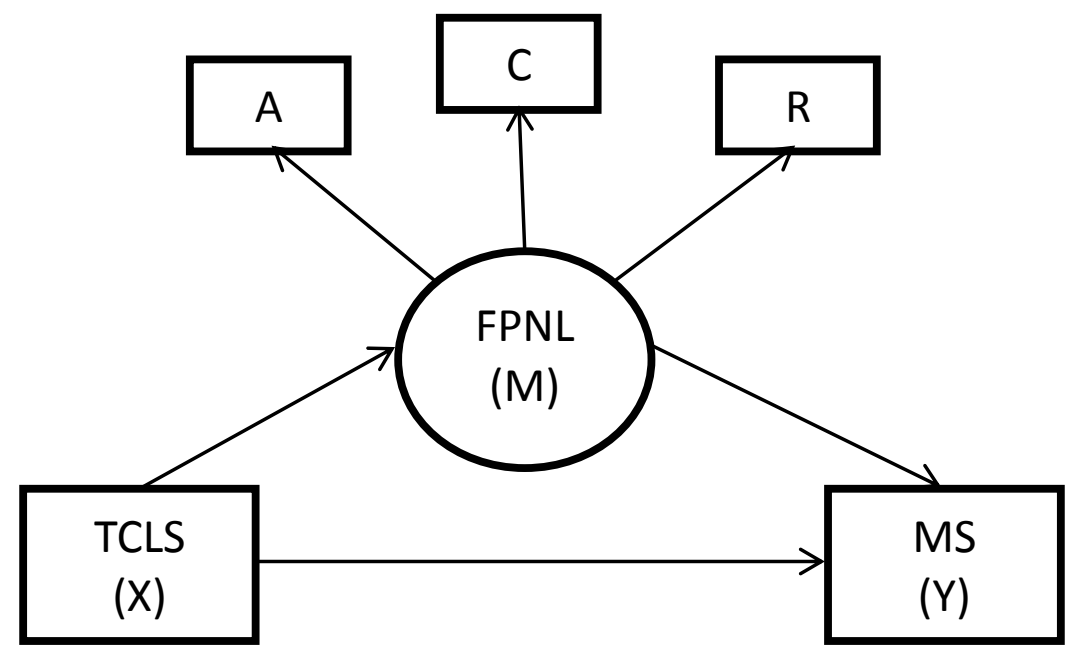

Figure 3. Model 5 - The combined mediating effects of autonomy (A), competence (C), and relatedness $(\mathrm{R})$. 


\section{References}

Ahlstrom, M., Lundberg, N. R., Zabriskie, R., Eggett, D., \& Lindsay, G. B. (2012). Me, my spouse, and my avatar: The relationship between marital satisfaction and playing massively multiplayer online role-playing games (MMORPGs). Journal of Leisure Research, 44(1), $1-22$.

Appleton, C., \& Bohm, E. (2001). Partners in passage: The experience of marriage in mid-life. Journal of Phenomenological Psychology, 32(1), 41-70.

Baldwin, J. H., Ellis, G. D., \& Baldwin, B. M. (1999). Marital satisfaction: An examination of its relationship to spouse support and congruence of commitment among runners. Leisure Sciences, 21(2), 117-131.

Baron, R. M., \& Kenny, D. A. (1986). The moderator-mediator variable distinction in social psychological research: Conceptual, strategic, and statistical considerations. Journal of Personality and Social Psychology, 51(6), 1173-1182.

Bedini, L. A., Gladwell, N. J., Dudley, W. N., \& Clancy, E. J. (2011). Mediation analysis of leisure, perceived stress, and quality of life in informal caregivers. Journal of Leisure Research, 43(2), 153-175.

Benson, P. R., \& Kersh, J. (2011). Marital quality and psychological adjustment among mothers of children with ASD: Cross-sectional and longitudinal relationships. Journal of Autism Developmental Disorders, 41(12), 1675-1685.

Berg, E. C., Trost, M., Schneider, I. E., \& Allison, M. T. (2001). Dyadic exploration of the relationship of leisure satisfaction, leisure time, and gender to relationship satisfaction. Leisure Sciences, 23(1), 35-46. 
Blais, M. R., Sabourin, S., Boucher, C., \& Vallerand, R. J. (1990). Toward a motivational model of couple happiness. Journal of Personality and Social Psychology, 59(5), 1021-1031.

Bradbury, T. N., Fincham, F. D., \& Beach, S. R. H. (2000). Research on the nature and determinants of marital satisfaction: A Decade in review. Journal of Marriage and Family, 62(4), 964-980.

Claxton, A., \& Perry-Jenkins, M. P. (2008). No fun anymore: Leisure and marital quality across the transition to parenthood. Journal of Marriage and Family, 70(1), 28-43.

Cornelius, T. J. (2003). A search model of marriage and divorce. Review of Economic Dynamics, $6(1), 135-155$.

Crawford, D. W., Houts, R. M., Huston, T. L., \& George, L. J. (2002). Compatibility, leisure, and satisfaction in marital relationships. Journal of Marriage and Family, 64(2), 433-449.

Deci, E. L., \& Ryan, R. M. (1987). The support of autonomy and the control of behavior. Journal of Personality and Social Psychology, 53(6), 1024-1037.

Deci, E. L., \& Ryan, R. M. (2000). The what and why of goal pursuits: Human needs and the selfdetermination of behavior. Psychological Inquiry, 11(4), 227-268.

Dew, J. \& Wilcox, W. B. (2011). If momma ain't happy: Explaining declines in marital satisfaction among new mothers. Journal of Marriage and Family, 73(1), 1-12.

Diener, E., Emmons, R.A., Larsen, R.J., \& Griffin, S. (1985). The satisfaction with life scale. Journal of Personality Assessment, 49(1), 71-75.

Gager, C. T., \& Sanchez, L. (2003). Two as one? Couples' perceptions of time spent together, marital quality, and the risk of divorce. Journal of Family Issues, 24(1), 21-50.

Gagne, M. \& Deci, E. (2005). Self-determination theory and work motivation. Journal of Organizational Behavior, 26(4), 331-362. 
Gaine, G. S., \& La Guardia, J. G. (2009). The unique contributions of motivations to maintain a relationship and motivations toward relational activities to relationship well-being. Motivation and Emotion, 33(2), 184-202.

Gaudreau, P., Fecteau, M. C., Perreault, S. (2010). Individual self-determination and relationship satisfaction of athletes in dyadic sports: Examining the moderating role of dyadic selfdetermination. Journal of Applied Sport Psychology, 22(1), 34-50.

Goff, S. J., Fick, D. S., \& Oppliger, R. A. (1997). The moderating effect of spouse support on the relation between serious leisure and spouses' perceived leisure-family conflict. Journal of Leisure Research, 29(1), 47- 60.

Goodsell, T. L., \& Harris, B. D. (2011). Family life and marathon running: Constraint, cooperation, and gender in a leisure activity. Journal of Leisure Research, 43(1), 80-109.

Gorchoff, S. M., John, O. P., \& Helson, R. (2008). Contextualizing change in marital satisfaction during middle age: An 18-year longitudinal study. Psychological Science, 19(11), 11941200.

Gotlib, I. H., Lewinsohn, P. M., \& Seeley, J. R. (1998). Consequences of depression during adolescence: Marital status and marital functioning in early adulthood. Journal of Abnormal Psychology, 107(4), 686-690.

Greenwood, J., Guner, N., Kocharkov, G., Santos, C. (2012). Technology and the changing family: A unified model of marriage, divorce, educational attainment and married female laborforce participation. National Bureau of Economic Research (NBER). Working Paper No. 17735.

Herridge, K. L., Shaw, S. M., \& Mannell, R. C. (2003). An exploration of women's leisure within heterosexual romantic relationships. Journal of Leisure Research, 35(3), 274-291. 
Holman, T. B., \& Epperson, A. (1984). Family and leisure: A review of the literature with research recommendations. Journal of Leisure Research, 16(4), 277-294.

Holman, T. B., \& Jacquart, M. (1988). Leisure-activity patterns and marital satisfaction: A further test. Journal of Marriage and the Family, 50(1), 69-77.

Johnson, H. A., Zabriskie, R. B., \& Hill, B. (2006). The contribution of couple leisure involvement, leisure time, and leisure satisfaction to marital satisfaction. Marriage and Family Review, 40(1), 69-91.

Kabeer, N. (2000). The Power to Choose: Bangladeshi Women and Labour market Decisions in London and Dhaka. London and New York: Verso.

Kabeer, N. (2007). Marriage, Motherhood and Masculinity in the Global Economy: Reconfigurations of Personal and Economic Life. Bringhton, UK: Institute of Development Studies.

Kleiber, D. A. (1999). Leisure experience and human development: A dialectical interpretation. New York, NY: Basic Books.

Kline, R. B. (2005). Principles and practice of structural equation modeling (2nd ed.). New York, NY: Guilford Press.

Knee, C. R., Patrick, H., Vietor, N. A., Nanayakkara, A., \& Neighbors, C. (2002). Selfdetermination as growth motivation in romantic relationships. Personality and Social Psychology Bulletin, 28(5), 609-619.

La Guardia, J. G., \& Patrick, H. (2008). Self-determination theory as a fundamental theory of close relationships. Canadian Psychology, 49(3), 201-209. 
La Guardia, J. G., Ryan, R. M., Couchman, C. E., \& Deci, E. L. (2000). Within-person variation in security of attachment: A self-determination theory perspective on attachment, need fulfillment, and well-being. Journal of Personality and Social Psychology, 79(3), 367-384.

Langer, A., Lawrence, E., \& Barry, R. A. (2008). Using a vulnerability-stress-adaptation framework to predict physical aggression trajectories in newlywed marriage. Journal of Consulting and Clinical Psychology, 76(5), 756-768.

Lavner, J. A., \& Bradbury, T. N. (2010). Patterns of change in marital satisfaction over the newlywed years. Journal of Marriage and Family, 72(5), 1171-1187.

Levenson, R. W., Carstensen, L. L., \& Gottman, J. M. (1993). Long-term marriage: Age, gender, and satisfaction. Psychology and Aging, 8(2), 301-313.

Lundberg, N. R. (2009). The therapeutic use of community-based sports and recreation in the development of self-determined behavior: A case study. Annual in Therapeutic Recreation, $17,11-17$.

MacKinnon, D. P., Fairchild, A. J., \& Fritz, M. S. (2007). Mediation analysis. Annual Review of Psychology, 58, 593-614.

MacKinnon, D. P., Lockwood, C. M., Hoffman, J. M., West, S. G., \& Sheets, V. (2002). A comparison of methods to test mediation and other intervening variable effects. Psychological Methods, 7(1), 83-104.

McCord, J. (1991). Family relationships, juvenile delinquency, and adult criminality. Criminology, 29(3), 397-417.

Mead, D. E. (2002). Marital distress, co-occurring depression, and marital therapy: A review. Journal of Marital and Family Therapy, 28(3), 299-314. 
Neff, L. A., \& Karney, B. R. (2007). Stress crossover in newlywed marriage: A longitudinal and dyadic perspective. Journal of Marriage and Family, 69(3), 594-607.

Orthner, D. (1975). Leisure activity patterns and marital satisfaction over the marital career. Journal of Marriage and the Family, 37(1), 91-102.

Orthner, D. K., \& Mancini, J. A. (1991). Benefits of leisure for family bonding. In B. L. Driver, P. J. Brown, \& G. L. Peterson, (Eds.), Benefits of leisure (pp. 215-247). State College, PA: Venture Publishing.

Patrick, H., Knee, C. R., Canevello, A., \& Lonsbary, C. (2007). The role of need fulfillment in relationship functioning and well-being: A self-determination theory perspective. Journal of Personality and Social Psychology, 92(3), 434-457.

Rehman, U. S., Janssen, E., Newhouse, S., Heiman, J., Holtzworth-Munroe, A., Fallis, E., \& Rafaeli, E. (2011). Marital satisfaction and communication behaviors during sexual and nonsexual conflict discussions in newlywed couples: A pilot study. Journal of Sex \& Marital Therapy, 37(2), 94-103.

Reis, H. T., Sheldon, K. M., Gable, S. L., Roscoe, J., \& Ryan, R. M. (2000). Daily well-being: The role of autonomy, competence, and relatedness. Personality \& social psychology bulletin, $26(4), 419-435$.

Ricard, N. C., Beaudry, S. G., \& Pelletier, L. G. (2012). Lovers with happy feet the interdependece of relationship and activity factors for individuals dancing with a romantic partner. Journal of Applied Social Psychology, 42(4), 939-963.

Rogers, S. J., \& Amato, P. R. (1997). Is marital quality declining? The evidence from two generations. Social Forces, 75(3), 1089-1100. 
Ryan, R. M., \& Deci, E. L. (2000). Self-determination theory and the facilitation of intrinsic motivation, social development, and wellbeing. American Psychologist, 55(1), 68-78.

Ryan, R. M., \& Deci, E. L. (2007). Active human nature: Self-Determination theory and the promotion and maintenance of sport, exercise, and health. In M. S. Hagger \& N. L. D. Chatzisarantis (Eds.), Intrinsic Motivation and Self-Determination in Exercise and Sport (pp. 1-19). Champaign, IL: Human Kinetics.

Saxbe, D. E., Repetti, R. L., \& Graesch, A. P. (2011). Time spent in housework and leisure: Links with parents' physiological recovery from work. Journal of Family Psychology, 25(2), 271281.

Saxbe, D. E., Repetti, R. L., \& Nishina, A. (2008). Marital satisfaction, recovery from work, and diurnal cortisol among men and women. Health Psychology, 27(1), 15-25.

Schaller, J. (2012). For richer, if not for poorer? Marriage and divorce over the business cycle. Journal of Population Economics. Retrieved from http://www.springerlink.com/content/n56u3557685xvw46/

Schneider, B., Ainbinder, A.M., \& Csikszentmihalyi, M. (2004). Stress and working parents. In J.T. Haworth \& A.J. Veal (Eds.), Work and Leisure (pp. 145-167). London: Routledge. Shaw, S. M. (1985). The meaning of leisure in everyday life. Leisure Sciences, 7(1), 1-24.

Skowron, E. A. (2000). The role of differentiation of self in marital adjustment. Journal of Counseling Psychology, 47(2), 229-237.

Slatcher, R. B., Robles, T. F., Repetti, R. L., \& Fellows, M. D. (2010). Momentary work worries, marital disclosure, and salivary cortisol among parents of young children. Psychosomatic Medicine, 72(9), 887-896. 
Sturge-Apple, M. L., Davies, P. T., \& Cummings E. M. (2006). Hostility and withdrawal in marital conflict: Effects on parental emotional unavailability and inconsistent discipline. Journal of Family Psychology, 20(2), 227-238.

Teachman, J. D., Tedrow, L. M., \& Crowder, K. D. (2000). The changing demography of America's families. Journal of Marriage and Family, 62(4), 1234-1246.

Twenge, J. M., Campbell, W. K., \& Foster, C. A. (2003). Parenthood and marital satisfaction: A meta-analytic review. Journal of Marriage and Family, 66(3), 574-583.

Ward, P. J., Barney, K., Lundberg, N., \& Zabriskie, R. B. (2013, accepted for publication). A Critical examination of couple leisure and the application of the core and balance model. Journal of Leisure Research.

Ward, P. J., Clark, T., Zabriskie, R., \& Morris, T. (2012). Paper/pencil versus online data collection: An exploratory study. Journal of Leisure Research, 44(4), 507-530.

Ward, P. J., Lundberg, N. R., Zabriskie, R. B., \& Berrett, K. (2009). Measuring marital satisfaction: A comparison of the revised dyadic adjustment scale and the satisfaction with married life scale. Marriage \& Family Review, 45(4), 412-429.

Weinstein, N., Hodgins, H. S., \& Ryan R. M. (2010). Autonomy and control in dyads Effects on interaction quality and joint creative performance. Personality and Social Psychology Bulletin, 36(12), 1603-1617.

Williamson, M., Zabriskie, R. B., Fellingham, G., Ward, P., \& Lundberg, N. (2013, under review). A National Examination of Couple Leisure and Marital Satisfaction: A Mixed Model Approach. Submitted to Leisure Science. 
Zabriskie, R. B. (2000). An examination of family and leisure behavior among families with middle school aged children. Unpublished doctoral dissertation, Indiana University, Bloomington, Indiana.

Zabriskie, R. B., \& McCormick, B. P. (2001). The influences of family leisure patterns on perceptions of family functioning. Family Relations, 50(3), 281-289. 
Appendix B: Instruments 


\section{Marital Activity Profile}

(MAP)

The following questions ask about the activities you do with your spouse. Please refer to the last year or so. These questions ask about groups of activities, so try to answer in terms of the group as opposed to any one specific example. This may require you to "average" over a few different activities. Don't worry about getting it exactly "right." Just give your best estimate.

Take a moment to look at the example below. This will give you some instruction on how to fill in your answers.

QUESTION: Do you participate in home-based activities (for example watching TV/videos, listening to music, reading books, singing, etc.) with your spouse?

First do you do these activities?

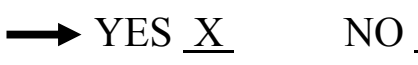

\begin{tabular}{|l|l|}
\hline \multicolumn{2}{|c|}{ If YES how often? } \\
\hline At least daily & \\
\hline At least weekly & $\mathrm{X}$ \\
\hline At least monthly & \\
\hline At least annually & \\
\hline
\end{tabular}
$\begin{aligned} & \text { Next, how often do } \\
& \text { you usually do these }\end{aligned}$

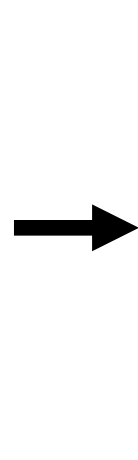

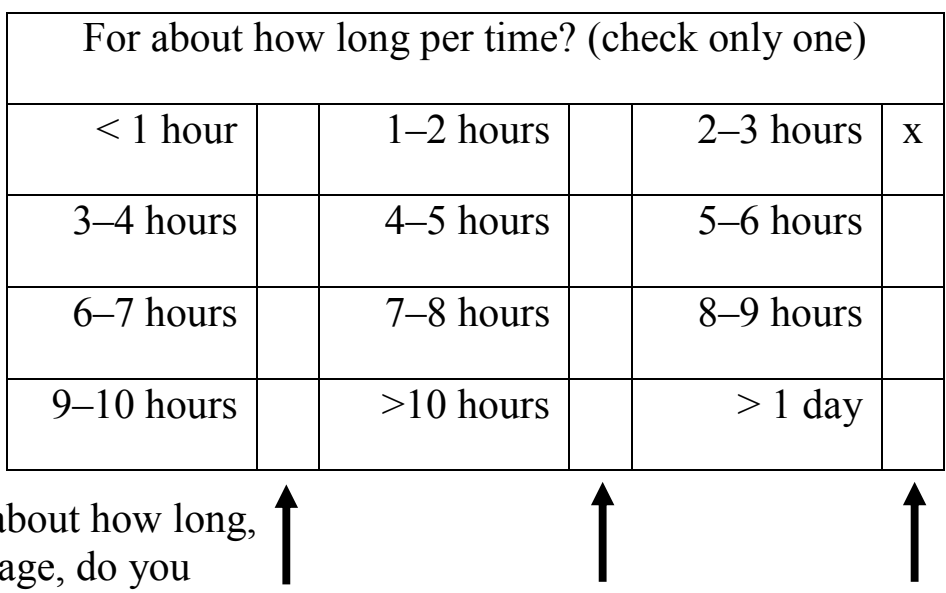
activities?

\section{Then, about how long, on average, do you} typically do this type of activity each time you do it?

Last, how satisfied are you with your participation with your spouse in these activities? Please answer this question EVEN IF YOU DO NOT do these activities with your spouse.

How satisfied are you with your level of participation with your spouse in these activities? (please circle one)

Very

Dissatisfied

1
Very

Satisfied 
1. Do you have dinners, at home, with your spouse?

YES

NO

\begin{tabular}{|l|l|}
\hline \multicolumn{2}{|c|}{ If YES how often? } \\
\hline At least daily & \\
\hline At least weekly & \\
\hline At least monthly & \\
\hline At least annually & \\
\hline
\end{tabular}

\begin{tabular}{|c|c|c|}
\hline \multicolumn{3}{|c|}{ For about how long per time? (check only one) } \\
\hline$<1$ hour & $1-2$ hours & $2-3$ hours \\
\hline $3-4$ hours & 4-5 hours & 5-6 hours \\
\hline
\end{tabular}

How satisfied are you with your level of participation with your spouse in these activities? (please circle one)

Very

Dissatisfied

1

2

3

4

Very

Satisfied

5

2. Do you participate in home-based activities (for example watching TV/videos, listening to music, reading books, singing, etc.) with your spouse?

YES _ $\quad \mathrm{NO}$

\begin{tabular}{|c|c|c|c|}
\hline If YES how often? & \multicolumn{3}{|c|}{ For about how long per time? (check only one) } \\
\hline At least daily & $<1$ hour & $1-2$ hours & $2-3$ hours \\
\hline At least weekly & 3-4 hours & 4-5 hours & $5-6$ hours \\
\hline At least monthly & $6-7$ hours & $7-8$ hours & $8-9$ hours \\
\hline At least annually & $9-10$ hours & $>10$ hours & $>1$ day \\
\hline
\end{tabular}

How satisfied are you with your level of participation with your spouse in these activities? (please circle one)

Very

Dissatisfied

1
2
3

4
Very

Satisfied

5 
3. Do you participate in household duties (for example preparation of meals, household maintenance, dishes, laundry, housework such as dusting, vacuuming, etc.) with your spouse?

YES _ NO N

\begin{tabular}{|c|c|c|c|}
\hline If YES how often & \multicolumn{3}{|c|}{ For about how long per time? (check only one) } \\
\hline At least daily & $<1$ hour & $1-2$ hours & $2-3$ hours \\
\hline At least weekly & 3-4 hours & $4-5$ hours & $5-6$ hours \\
\hline At least monthly & 6-7 hours & $7-8$ hours & $8-9$ hours \\
\hline At least annually & 9-10 hours & $>10$ hours & $>1$ day \\
\hline
\end{tabular}

How satisfied are you with your level of participation with your spouse in these activities? (please circle one)

Very

Dissatisfied

1

2

3

4

Very

Satisfied

5

4. Do you participate in games, crafts, and/or hobbies (for example playing cards, board games, video games, drawing, scrap books, sewing, painting, ceramics, home improvement projects, etc.) with your spouse?

YES

$\mathrm{NO}$

\begin{tabular}{|l|l|}
\hline \multicolumn{2}{|c|}{ If YES how often? } \\
\hline At least daily & \\
\hline At least weekly & \\
\hline At least monthly & \\
\hline At least annually & \\
\hline
\end{tabular}

\begin{tabular}{|r|r|r|r|r|}
\hline \multicolumn{5}{|c|}{ For about how long per time? (check only one) } \\
\hline$<1$ hour & $1-2$ hours & $2-3$ hours & \\
\hline $3-4$ hours & $4-5$ hours & $5-6$ hours & \\
\hline $6-7$ hours & $7-8$ hours & $8-9$ hours & \\
\hline $9-10$ hours & $>10$ hours & $>1$ day & \\
\hline
\end{tabular}

How satisfied are you with your level of participation with your spouse in these activities? (please circle one)

Very

Dissatisfied

1

2

3

4

Very

Satisfied

5 
5. Do you participate in regular talking (for example visiting, extended discussions, talking before retiring to bed, etc.) with your spouse?

YES _ NO

\begin{tabular}{|c|c|c|c|}
\hline If YES how often? & \multicolumn{3}{|c|}{ For about how long per time? (check only one) } \\
\hline At least daily & $<1$ hour & $1-2$ hours & $2-3$ hours \\
\hline At least weekly & $3-4$ hours & 4-5 hours & $5-6$ hours \\
\hline At least monthly & 6-7 hours & $7-8$ hours & $8-9$ hours \\
\hline At least annually & $9-10$ hours & $>10$ hours & $>1$ day \\
\hline
\end{tabular}

How satisfied are you with your level of participation with your spouse in these activities? (please circle one)

Very

Dissatisfied

1

2

3

4

Very

Satisfied

5

6. Do you participate in home-based or neighborhood based activities (for example star gazing, gardening, yard work, playing catch, shooting baskets, bike rides, fitness activities, exercise, etc.) with your spouse?

YES

NO

\begin{tabular}{|l|l|}
\hline \multicolumn{2}{|c|}{ If YES how often? } \\
\hline At least daily & \\
\hline At least weekly & \\
\hline At least monthly & \\
\hline At least annually & \\
\hline
\end{tabular}

For about how long per time? (check only one)

\begin{tabular}{|r|r|r|r|r|r|}
\hline$<1$ hour & $1-2$ hours & $2-3$ hours & \\
\hline $3-4$ hours & & $4-5$ hours & & $5-6$ hours & \\
\hline $6-7$ hours & & $7-8$ hours & & $8-9$ hours & \\
\hline $9-10$ hours & & $>10$ hours & & $>1$ day & \\
\hline
\end{tabular}

How satisfied are you with your level of participation with your spouse in these activities? (please circle one)

Very

Dissatisfied

1
Very

Satisfied

4

5 
7. Do you attend and support your spouse's individual activities (for example watching their sporting events, musical performances, school/work programs and presentations, etc.)?

YES _ NO N

\begin{tabular}{|c|c|c|c|}
\hline If YES how oft & For about & ng per time & k only one) \\
\hline At least daily & $<1$ hour & $1-2$ hours & $2-3$ hours \\
\hline At least weekly & 3-4 hours & 4-5 hours & $5-6$ hours \\
\hline At least monthly & 6-7 hours & $7-8$ hours & 8-9 hours \\
\hline At least annually & 9-10 hours & $>10$ hours & $>1$ day \\
\hline
\end{tabular}

How satisfied are you with your participation with family members in these activities? (please circle one)

Very

Dissatisfied

1

2

3

4

Very
Satisfied
5

5

8. Do you participate in religious/spiritual activities (for example going to church activities, worshipping, scripture reading, couple prayer, gospel discussions, etc.) with your spouse?

YES

NO

\begin{tabular}{|l|l|}
\hline \multicolumn{2}{|c|}{ If YES how often? } \\
\hline At least daily & \\
\hline At least weekly & \\
\hline At least monthly & \\
\hline At least annually & \\
\hline
\end{tabular}

For about how long per time? (check only one)

\begin{tabular}{|c|c|c|}
\hline$<1$ hour & 1-2 hours & $2-3$ hours \\
\hline 3-4 hours & 4-5 hours & $5-6$ hours \\
\hline 6-7 hours & $7-8$ hours & 8-9 hours \\
\hline 9-10 hours & $>10$ hours & $>1$ day \\
\hline
\end{tabular}

How satisfied are you with your level of participation with your spouse in these activities? (please circle one)

Very

Dissatisfied

1

2

3

4

Very

Satisfied

5 
9. Do you participate in community-based social activities (for example going to restaurants,parties, shopping, visiting friends and neighbors, picnics, etc.) with your spouse?

YES _ NO NO

\begin{tabular}{|c|c|c|c|}
\hline If YES how oft & For about & ng per time & k only one) \\
\hline At least daily & $<1$ hour & $1-2$ hours & $2-3$ hours \\
\hline At least weekly & 3-4 hours & $4-5$ hours & 5-6hours \\
\hline At least monthly & 6-7 hours & $7-8$ hours & 8-9 hours \\
\hline At least annually & $9-10$ hours & $>10$ hours & $>1 \mathrm{day}$ \\
\hline
\end{tabular}

How satisfied are you with your level of participation with your spouse in these activities? (please circle one)

Very

Dissatisfied

1

2

3

4

Very

Satisfied

5

10. Do you participate in spectator activities (for example going to movies, sporting events, concerts, plays or theatrical performances, etc.) with your spouse?

YES

NO

\begin{tabular}{|l|l|}
\hline \multicolumn{2}{|c|}{ If YES how often? } \\
\hline At least daily & \\
\hline At least weekly & \\
\hline At least monthly & \\
\hline At least annually & \\
\hline
\end{tabular}

For about how long per time? (check only one)

\begin{tabular}{|c|c|c|}
\hline$<1$ hour & $1-2$ hours & $2-3$ hours \\
\hline 3-4 hours & $4-5$ hours & $5-6$ hours \\
\hline 6-7 hours & $7-8$ hours & 8-9 hours \\
\hline 9-10 hours & $>10$ hours & $>1$ day \\
\hline
\end{tabular}

How satisfied are you with your level of participation with your spouse in these activities? (please circle one)

Very

Dissatisfied

1

2

3

4

Very

Satisfied 
11. Do you participate in community-based sporting activities (for example bowling, golf, swimming, skating, working out at the gym, etc.) with your spouse?

YES

$\mathrm{NO}$

If YES how often?

At least daily

At least weekly

At least monthly

At least annually

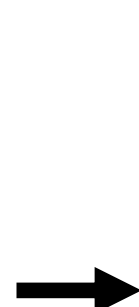

\begin{tabular}{|c|c|c|}
\hline \multicolumn{3}{|c|}{ For about how long per time? (check only one) } \\
\hline$<1$ hour & $1-2$ hours & $2-3$ hours \\
\hline $3-4$ hours & 4-5 hours & $5-6$ hours \\
\hline 6-7 hours & $7-8$ hours & $8-9$ hours \\
\hline $9-10$ hours & $>10$ hours & $>1$ day \\
\hline
\end{tabular}

How satisfied are you with your level of participation with your spouse in these activities? (please circle one)

Very

Dissatisfied

1

2

3

4

Very

Satisfied

5 
12. Do you participate in community-based special events (for example visiting museums, zoos, theme parks, fairs, etc.) with your spouse?

YES _ NO

\begin{tabular}{|l|l|}
\hline \multicolumn{2}{|c|}{ If YES how often? } \\
\hline At least daily & \\
\hline At least weekly & \\
\hline At least monthly & \\
\hline At least annually & \\
\hline
\end{tabular}

\begin{tabular}{|r|r|r|r|r|}
\hline \multicolumn{5}{|c|}{ For about how long per time? (check only one) } \\
\hline$<1$ hour & $1-2$ hours & $2-3$ hours & \\
\hline $3-4$ hours & $4-5$ hours & $5-6$ hours & \\
\hline $6-7$ hours & $7-8$ hours & $8-9$ hours & \\
\hline $9-10$ hours & $>10$ hours & & \\
\hline 1 day & 8 days & 15 days & \\
\hline 2 days & 9 days & 16 days & \\
\hline 3 days & 10 days & 17 days & \\
\hline 4 days & 11 days & 18 days & \\
\hline 5 days & 12 days & 19 days & \\
\hline 6 days & 13 days & 20 days & \\
\hline One week & Two weeks & 3 or more & weeks & \\
\hline & & & & \\
\hline
\end{tabular}

How satisfied are you with your level of participation with your spouse in these activities? (please circle one)

Very

Dissatisfied

1
Very

Satisfied

4
5 
13. Do you participate in outdoor activities (for example camping, hiking, hunting, fishing, boating, water skiing, canoeing etc.) with your spouse?

YES _ N N

\begin{tabular}{|l|l|}
\hline \multicolumn{2}{|c|}{ If YES how often? } \\
\hline At least daily & \\
\hline At least weekly & \\
\hline At least monthly & \\
\hline At least annually & \\
\hline
\end{tabular}

\begin{tabular}{|r|r|r|r|r|}
\hline \multicolumn{5}{|c|}{ For about how long per time? (check only one) } \\
\hline$<1$ hour & $1-2$ hours & $2-3$ hours & \\
\hline $3-4$ hours & $4-5$ hours & $5-6$ hours & \\
\hline $6-7$ hours & $7-8$ hours & $8-9$ hours & \\
\hline $9-10$ hours & $>10$ hours & & \\
\hline 1 day & 8 days & 15 days & \\
\hline 2 days & 9 days & 16 days & \\
\hline 3 days & 10 days & 17 days & \\
\hline 4 days & 11 days & 18 days & \\
\hline 5 days & 12 days & 19 days & \\
\hline 6 days & 13 days & 20 days & \\
\hline One week & Two weeks & $\begin{array}{r}3 \text { or more } \\
\text { weeks }\end{array}$ & \\
\hline
\end{tabular}

How satisfied are you with your level of participation with your spouse in these activities? (please circle one)

Very

Dissatisfied

1

2

3

4

Very

Satisfied

5 
14. Do you participate in outdoor adventure activities (for example rock climbing, river rafting, off-road vehicles, scuba diving, etc.) with your spouse?

YES _ NO N

\begin{tabular}{|l|l|}
\hline \multicolumn{2}{|c|}{ If YES how often? } \\
\hline At least daily & \\
\hline At least weekly & \\
\hline At least monthly & \\
\hline At least annually & \\
\hline
\end{tabular}

\begin{tabular}{|r|r|r|r|r|}
\hline \multicolumn{5}{|c|}{ For about how long per time? (check only one) } \\
\hline$<1$ hour & $1-2$ hours & $2-3$ hours & \\
\hline $3-4$ hours & $4-5$ hours & $5-6$ hours & \\
\hline $6-7$ hours & $7-8$ hours & $8-9$ hours & \\
\hline 9-10 hours & $>10$ hours & & \\
\hline 1 day & 8 days & 15 days & \\
\hline 2 days & 9 days & 16 days & \\
\hline 3 days & 10 days & 17 days & \\
\hline 4 days & 11 days & 18 days & \\
\hline 5 days & 12 days & 19 days & \\
\hline 6 days & 13 days & 20 days & \\
\hline One week & Two weeks & 3 or more & weeks & \\
\hline & & & & \\
\hline
\end{tabular}

How satisfied are you with your level of participation with your spouse in these activities? (please circle one)

Very

Dissatisfied

1
Very

Satisfied

5 
15. Do you participate in tourism activities (for example couple vacations, traveling, visiting historic sites, visiting state/national parks, etc.) with your spouse?

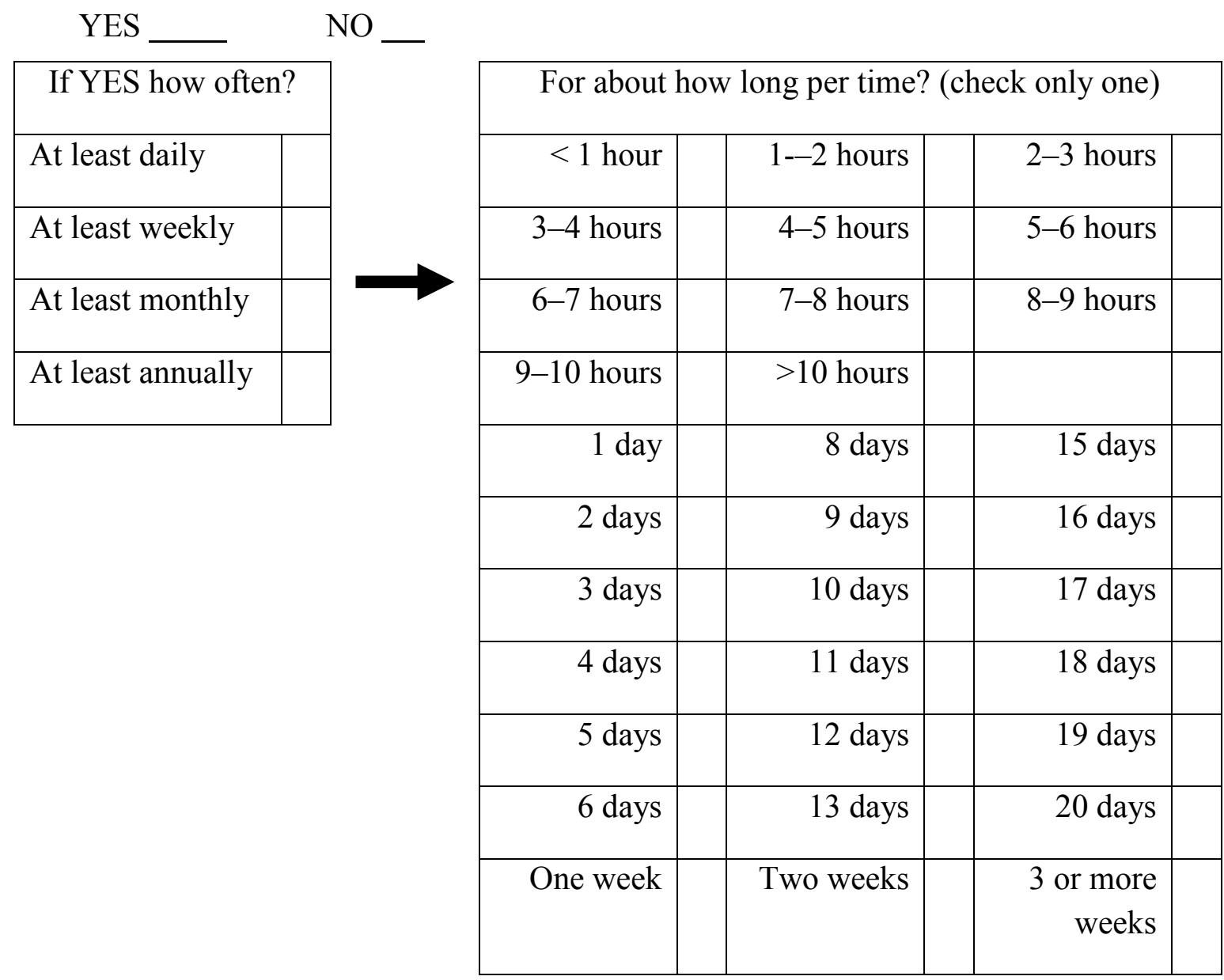

How satisfied are you with your level of participation with your spouse in these activities? (please circle one)

Very

Dissatisfied

1
Very

Satisfied

4

5 


\section{Fulfillment of Psychological Needs during Couple Leisure (FPNL)}

For the following statements, use the scale below.

$$
\begin{aligned}
& 1=\text { Not Very True At All } \\
& 4=\text { Somewhat True } \\
& 7=\text { Very True }
\end{aligned}
$$

1. During our recreation participation, I feel free to $\quad \square 1$ be who I am.

2. During our recreation participation, I feel like a $\quad \square 3$ competent person. $\quad \square \quad 4$

3. During our recreation participation, I often feel $\square 5$ loved and cared about.

4. During our recreation participation, I often feel inadequate or incompetent.

5. During our recreation participation, I have a say in what happens, and I can voice my opinion.

6. During our recreation participation, I often feel a lot of distance in our relationship.

7. During our recreation participation, I feel very capable and effective.

8. During our recreation participation, I feel a lot of closeness and intimacy.

9. During our recreation participation, I feel controlled and pressured to be certain ways. 


\section{Satisfaction with Married Life (SWML)}

Below are seven statements with which you may agree or disagree. Using the 1-7 scale below, indicate your agreement with each item by circling the appropriate number on the line following that item. Please be open and honest in responding.

$\begin{array}{ccccccc}1 & 2 & 3 & 4 & 5 & 6 & 7 \\ \text { Strongly } & \text { Disagree } & \begin{array}{c}\text { Slightly } \\ \text { disagree }\end{array} & \begin{array}{c}\text { Neither agree } \\ \text { nor disagree }\end{array} & \begin{array}{c}\text { Slightly } \\ \text { agree }\end{array} & \text { Agree } & \begin{array}{c}\text { Strongly } \\ \text { agree }\end{array}\end{array}$

1. In most ways my married life is close to ideal

$\begin{array}{lllllll}1 & 2 & 3 & 4 & 5 & 6 & 7\end{array}$

2. The conditions of my married life are excellent.

$\begin{array}{lllllll}1 & 2 & 3 & 4 & 5 & 6 & 7\end{array}$

3. I am satisfied with my married life.

$\begin{array}{lllllll}1 & 2 & 3 & 4 & 5 & 6 & 7\end{array}$

4. So far I have gotten the important things I want in my married life $\begin{array}{llllllll}1 & 2 & 3 & 4 & 5 & 6 & 6\end{array}$

5. If I could live my married life over, I would change almost

$\begin{array}{lllllll}1 & 2 & 3 & 4 & 5 & 6 & 7\end{array}$
nothing 